\title{
UTILIZAÇĀO DO MÉTODO BOOTSTRAP NA ESCOLHA ENTRE OS MODELOS DE COX E LOGÍSTICO PARA DADOS DE SOBREVIVÊNCIA COM CENSURA INTERVALAR
}

\section{JEANETE ALVES MOREIRA}

Bacharel em Estatística

Orientador: Prof. Dr. JOSÉ EDUARDO CORRENTE

\begin{abstract}
Tese apresentada à Escola Superior de Agricultura "Luiz de Queiroz", Universidade de São Paulo, para a obtenção do título de Doutor em Agronomia, Área de Concentração: Estatística e Experimentação Agronômica.
\end{abstract}

PIRACICABA

Estado de São Paulo - Brasil

Outubro - 2001 


\begin{tabular}{|c|c|c|c|}
\hline PÁGINA & LINHA & ONDE SE LÊ & LEIA-SE \\
\hline xii & 13 & deviances & deviances \\
\hline 6 & 13 & instantânea & instantâneo \\
\hline 14 & 23 & it bootstrap & bootstrap \\
\hline 17 & 1 & $\mathrm{~F}$ & $F$ \\
\hline 18 & 6 & a a & $\mathrm{a}$ \\
\hline 19 & 24 & desenvolveu & desenvolveram \\
\hline 22 & 3 & considerando-se & considere-se \\
\hline 22 & 14 & sobrevivência & sobrevivência, \\
\hline 24 & 6 & 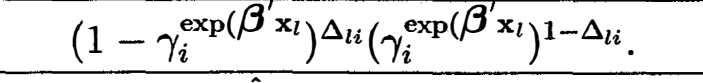 & $\left(1-\gamma_{i}^{\exp \left(\boldsymbol{\beta}^{\prime} \mathbf{x}_{l}\right)}\right)^{\Delta_{l i}}\left(\gamma_{i}^{\exp \left(\boldsymbol{\beta}^{\prime} \mathbf{x}_{l}\right)}\right)^{1-\Delta_{l i}}$ \\
\hline 29 & 2 & $r_{P i}=\frac{y_{i}-\hat{\mu_{i}}}{\left[V\left(\mu_{i}\right)\right]^{1 / 2}}, \quad i=1,2, \ldots, n$ & $r_{P i}=\frac{y_{i}-\hat{\mu_{i}}}{\left[V\left(\hat{\mu_{i}}\right)\right]^{1 / 2}}, \quad i=1,2, \ldots, n$ \\
\hline 30 & 1 & $\hat{\mu}$ & $\hat{y}$ \\
\hline 30 & 4 & $y_{\text {bootPi}}^{*}=\hat{\mu}+V\left(\hat{\mu}_{i}\right) \varepsilon_{P i}^{*}$ & $y_{\text {bootPi}}^{*}=\hat{y}+V\left(\hat{\mu}_{i}\right) \varepsilon_{P i}^{*}$ \\
\hline 30 & 8 & $\left.y_{b o o t P P i}^{*}=\hat{\mu}+c_{i} \hat{k} V\left(\hat{\mu}_{i}\right)\left(1-h_{i}\right)\right]^{1 / 2} \varepsilon_{P P i}^{*}$ & $\left.y_{b o o t P P i}^{*}=\hat{y}+c_{i} \hat{k} V\left(\hat{\mu}_{i}\right)\left(1-h_{i}\right)\right]^{1 / 2} \varepsilon_{P P i}^{*}$ \\
\hline 33 & 5 & construiu-se & construiram-se \\
\hline 57 & 11 & utilizar o esta & utilizar esta \\
\hline
\end{tabular}

\section{ERRATA DAS TABELAS}

- página 34 Tabela 4 - onde se lê Nula, leia-se modelo nula

- página 35 Tabela 5 - onde se lê $\alpha_{2}^{*}$, leia-se $\alpha_{2}$

- página 35 Tabela 5 - onde se lê $\alpha_{3}^{*}$, leia-se $\alpha_{3}$

- página 35 Tabela 5 - onde se lê $\alpha_{4}^{*}$, leia-se $\alpha_{4}$ 


\section{Dados Internacionais de Catalogação na Publicação (CIP)}

DIVISÃO DE BIBLIOTECA E DOCUMENTAÇÃO - ESALQ/USP

Moreira, Jeanete Alves

Utilização do método Bootstrap na escolha entre os modelos de cox e logistico para dados de sobrevivência com censura intervalar / Jeanete Alves Moreira. - - Piracicaba, 2001.

$65 \mathrm{p}$.

Tese (doutorado) - Escola Superior de Agricultura Luiz de Queiroz, 2001. Bibliografia.

1. Estatística agricola 2. Experimento agrícola 3. Decisão estatística 4. Modelo matemático l. Título

CDD 630.2195

Mermitida a copiat total ou parcial deste documento, desdeque citada a fonte - O autop 


\section{DEDICATÓRIA}

A minha força maior,

\section{Deus}

És a minha fortaleza, meu refúgio e meu grande guia. A ti entreguei a minha vida e hoje não poderia deixar de te dedicar o meu trabalho.

Ao meu pai,

João Moreira, pelo grande estímulo, dedicação e amor e a minha mãezinha Maria da Salete (in memoriam), os anos passaram... e, apesar de não tê-la mais por perto, sinto um enorme orgulho de ser sua filha e sempre levarei comigo seu exemplo de coragem e alegria de viver.

Aos meus filhos

Matheus e João Augusto, na inocência vocês não sabem avaliar a grandiosidade deste momento, mas saibam que vocês, meus pequenos príncipes, foram um grande estímulo para que eu chegasse até aqui.

Amo vocês. 


\title{
AGRADECIMENTOS
}

\author{
A Deus \\ No mundo tereis afliç̃es, mas tendes bom \\ ânimo, eu venci o mundo.
}

João 16:33.

Ao conquistarmos um objetivo sempre temos muito a agradecer e durante esse período conheci pessoas que me estenderam as mãos e me ajudaram bastante a conviver com a distância e a saudade. Portanto, registro aqui meus agradecimentos a todos aqueles que de algum modo colaboraram para a realização deste trabalho e consequentemente para minha maturidade.

Ao Prof. Dr. José Eduardo Corrente, meu orientador e meu amigo, pela orientação, dedicação e confiança que muito contribuiram para que eu chegasse até aqui. Você é muito especial para mim.

Às prof ${ }^{a s}$ Dr. $^{a s}$ Clarice Garcia Borges Demétrio e Maria Cristina Stolf Nogueira, pelos ensinamentos, orientações e atenção.

A prof ${ }^{a}$ Dr. $^{a}$ Liciana Vaz de Arruda S. Chalita, pelos esclarecimentos, troca de idéias e principalmente pelo seu carinho.

Aos professores e funcionários do Departamento de Ciências Exatas da ESALQ USP, pelo carinho, respeito e amizade.

Aos professores e funcionários do Departamento de Estatística da UFRN, pelo apoio, estímulo e credibilidade. 
Ao programa PICDT/CAPES, pela bolsa de estudos concedida.

Aos professores Francisco Canindé de Oliveira e Robson Santana Pacheco do Departamento de Matemática da UFRN pela contribuição e amizade.

A minha família pelo apoio e palavras de conforto, feliz de quem tem uma família e nela pode buscar o mais nobre dos sentimentos, o amor.

A minha irmã Josilete Alves M. de Azevêdo, pela grande ajuda nas correções do Português e seu incentivo constante.

A minha querida sobrinha Ângela Patrícia pela sua dedicação e amor.

Ao Augusto que soube suportar com paciência a saudade dos nossos filhos e por ter me apoiado nesta decisão.

À Maria Helena, pela sua presença amiga/irmã em todas as horas, pelo seu estímulo e carinho sempre presentes em minha vida.

Às amigas Denise e Sílvia, vocês foram mais que amigas, vocês foram irmãs.

Aos amigos da Pós-graduação, pela convivência agradável, pelo carinho e amizade que tornaram momentos difíceis em momentos de muita alegria, em especial ao Afrânio, Adilson, Cristián, Wilson, Sandra, Cecília, Lêda, Suely, Silvano, André, Maria Cristina, Jomar, Heyder e a turma do mestrado/2000.

A Gilmara, pelo seu abraço amigo e grande incentivo nesta etapa final.

Ao Idemauro, em um mundo de muita maldade e ambições encontrar pessoas com a sua dignidade nos faz acreditar que ainda vale a pena investir no ser humano. Obrigada pelo seu companheirismo e amizade.

Aos meus filhinhos Matheus e João Augusto, pelo amor infinito que nos une. 


\section{SUMÁRIO}

Página

LISTA DE FIGURAS

vii

LISTA DE TABELAS

ix

RESUMO

xi

SUMMARY

xiii

1 INTRODUÇÃO

2 REVISĀO DE LITERATURA 4

2.1 Análise de sobrevivência $\ldots \ldots \ldots \ldots$

2.2 Modelos lineares generalizados . . . . . . . . . . . . . . . . . 12

$2.3 \quad \mathrm{O}$ método bootstrap $\ldots \ldots \ldots \ldots \ldots$

2.4 Seleção de modelos . . . . . . . . . . . . . . . . . . . 17

3 METODOLOGIA $\quad 22$

3.1 Modelos para dados com censura intervalar . . . . . . . . . . . . 22

3.1 .1 Modelo de riscos proporcionais de Cox . . . . . . . . . . . 23

3.1 .2 Modelo $\operatorname{logístico~\ldots .~\ldots ~.~.~.~.~.~.~.~.~.~.~.~.~.~} 25$

3.2 Utilização dos modelos lineares generalizados para o ajuste dos modelos logístico e de $\operatorname{Cox} \ldots \ldots \ldots \ldots \ldots \ldots$

3.3 Planos de reamostragem . . . . . . . . . . . . . . . 27

3.3 .1 Obtenção das amostras bootstrap $\ldots \ldots \ldots$. . . . . . . . . 29 
3.4 Aplicações . . . . . . . . . . . . . . . . . . 30

3.4 .1 Aplicação em Fitopatologia . . . . . . . . . . . . . 30

3.4.2 Aplicação em Entomologia . . . . . . . . . . . . . . . 31

4 RESUltados E DISCUSSĀO 33

4.1 Aplicação com cultivar de linho . . . . . . . . . . . . . . 33

4.2 Aplicação com inseto . . . . . . . . . . . . . . . . . 43

5 CONCLUSÕES $\quad 56$

$\begin{array}{ll}\text { REFERÊNCIAS BIBLIOGRÁFICAS } & 58\end{array}$

$\begin{array}{lc}\text { APÊNDICE } & 63\end{array}$ 


\section{LISTA DE FIGURAS}

Página

1 Curvas de sobrevivência estimadas pela tabela de vida versus tempo de vida em dias para cada substrato. . . . . . . . . . . . . . . . . 33

2 Curva de sobrevivência segundo o tipo de solo ajustada para o modelo de

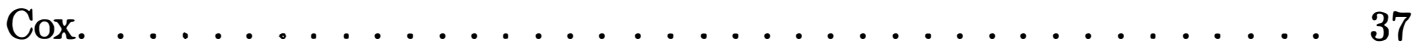

3 Curva de sobrevivência segundo o tipo de solo ajustada para o modelo logístico. . . . . . . . . . . . . . . . . . 37

4 Histograma da distribuição da diferença de deviances obtidas através de 1000 replicações bootstrap considerando os resíduos simples no ajuste dos modelos de Cox e logístico para os dados do experimento com cultivar de linho.

5 Histograma da distribuição da diferença de deviances obtidas através de 1000 replicações bootstrap considerando os resíduos de Pearson no ajuste dos modelos de Cox e logístico para os dados do experimento com cultivar de linho. . . . . . . . . . . . . . . . . . . . . . . .

6 Histograma da distribuição da diferença de deviances obtidas através de 1000 replicações bootstrap considerando os resíduos de Pearson padronizados no ajuste dos modelos de Cox e logístico para os dados do experimento com cultivar de linho. . . . . . . . . . . . . . . . . . . 42

7 Curva de sobrevivência estimadas segundo o sexo - Modelo de Cox. . . . 45

8 Curva de sobrevivência segundo o sexo - Modelo logístico. . . . . . . . . 45

9 Curva de sobrevivência segundo o grupo - Modelo de Cox. . . . . . . . . 46 
10 Histograma das diferenças de deviances obtidas através de 1000 replicações bootstrap dos resíduos simples no ajuste dos modelos de Cox e logístico (com o fator grupo) para os dados do experimento com inseto. . 49

11 Histograma das diferenças de deviances obtidas através de 1000 replicações bootstrap dos resíduos de Pearson no ajuste dos modelos de Cox e logístico (com o fator grupo) para os dados do experimento com inseto. . 50

12 Histograma das diferenças de deviances obtidas através de 1000 replicações bootstrap dos resíduos de Pearson padronizados no ajuste dos modelos de Cox e logístico (com o fator grupo) para os dados do experimento

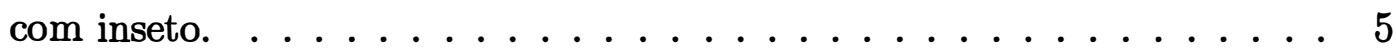

13 Histogramas das diferenças de deviances obtidas através de 1000 replicações bootstrap considerando-se os resíduos simples no ajuste dos modelos de Cox e logístico para os dados do experimento com inseto (sem o

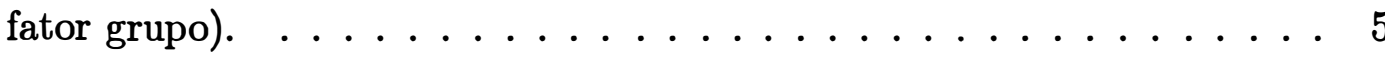

14 Histogramas das diferenças de deviances obtidas através de 1000 replicações bootstrap considerando-se os resíduos de Pearson no ajuste dos modelos de Cox e logístico para os dados do experimento com inseto (sem o fator grupo). . . . . . . . . . . . . . . . . . . . 54

15 Histogramas das diferenças de deviances obtidas através de 1000 replicações bootstrap considerando-se os resíduos de Pearson padronizados no ajuste dos modelos de Cox e logístico para os dados do experimento com inseto $($ sem o fator grupo) . . . . . . . . . . . . . . . . . . . 55 


\section{LISTA DE TABELAS}

Página

1 Relação entre proporções de empates (pe) e o modelo a ser utilizado, para amostras de tamanho 20 e $50 \ldots \ldots \ldots \ldots$

2 Relação entre proporções de empates (pe) e o modelo a ser utilizado, para amostras de tamanho 100 e $200 \ldots \ldots \ldots$. . . . . . . . . . . 11

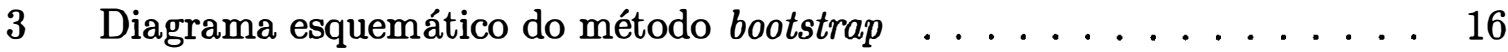

4 Análise de deviances do experimento com o cultivar de linho. . . . . . . . 34

5 Estimativas dos parâmetros obtidas através dos ajustes dos modelo de Cox e logístico para os dados do experimento com cultivar de linho. . . . 35

6 Razão de risco e $p$-valor segundo o modelo adotado - Experimento com o cultivar de linho. . . . . . . . . . . . . . . . . . . 36

7 Níveis de significância obtidos através de 1000 replicações bootstrap segundo o tipo de resíduo e os modelos de Cox e logístico para os dados do experimento com o cultivar de linho. . . . . . . . . . . . . . . 39

8 Análise de deviances do experimento com inseto para os modelos de Cox e $\log$ ístico. . . . . . . . . . . . . . . . . . . . . . 43

$9 \quad$ Estimativas dos parâmetros obtidas através do ajuste do modelo de Cox para os dados do experimento com insetos. . . . . . . . . . . . . 46

10 Estimativas dos parâmetros obtidas através do ajuste do modelo logístico para os dados do experimento com insetos. . . . . . . . . . . . . . 47

11 Razão de risco e $p$-valor segundo o modelo adotado. . . . . . . . . . . 47 
12 Níveis de significância obtidos através de 1000 replicações bootstrap segundo o tipo de resíduo e os modelo de Cox e logístico (com grupo) para o experimento com inseto. . . . . . . . . . . . . . . . . . . 48

13 Níveis de significância obtidos através de 1000 replicações bootstrap segundo o tipo de resíduo e os modelo de Cox e logístico (sem grupo) Experimento com inseto. . . . . . . . . . . . . . . . 52 


\title{
UTILIZAÇĀO DO MÉTODO BOOTSTRAP NA ESCOLHA ENTRE OS MODELOS DE COX E LOGÍSTICO PARA DADOS DE SOBREVIVENNCIA COM CENSURA INTERVALAR
}

\author{
Autora: JEANETE ALVES MOREIRA \\ Orientador: Prof. Dr. JOSÉ EDUARDO CORRENTE
}

\section{RESUMO}

Em muitos trabalhos científicos, o interesse dos pesquisadores está em identificar variáveis ou fatores que influenciem no tempo de ocorrência de um determinado evento, o qual geralmente é conhecido como tempo de falha. Nem sempre, porém, é possível observar o tempo exato de ocorrência da falha, conhecendo-se somente o intervalo em que a mesma ocorreu. Dados deste tipo são conhecidos como agrupados ou de sobrevivência com censura intervalar e apresentam observações empatadas. Quando o número de empates é pequeno, a análise desses dados pode ser feita através do ajuste do modelo de Cox (Cox, 1972) considerando-se aproximações para a verossimilhança parcial. No caso de ocorrerem muitos empates, deve-se considerar o tempo como discreto e modelar a probabilidade de ocorrência do evento num determinado intervalo, dado que ele não ocorreu no intervalo imediatamente anterior. 
Isto pode ser feito considerando-se a variável resposta como uma variável indicadora de falha, que é binária, e ajustando-se os modelos de Cox para dados agrupados ou o modelo logístico, através dos modelos lineares generalizados com funções de ligação complemento $\log$-log e logit, respectivamente. Após o ajuste dos modelos, existe o interesse em selecionar qual deles melhor se adequa aos dados experimentais. Para isto, algumas técnicas de seleção de modelos estão disponíveis na literatura, como o Critério de Informação de Akaike (Akaike, 1973), os Testes Escores propostos por Colosimo et al. (2000), dentre outras. Este trabalho propõe uma nova metodologia para a seleção entre os modelos de Cox e logístico para dados de sobrevivência com censura intervalar, utilizando o método de reamostragem bootstrap dos resíduos. Isto é feito extraindo-se os resíduos dos ajustes dos modelos propostos e calculando-se a diferença de deviances entre os modelos ajustados. Após isto, as novas observações são recompostas a partir dos resíduos bootstrap e novas diferenças de deviances são calculadas. Um histograma para esses valores é, então, obtido e um nível de significância empírico é proposto comparando-se os valores das diferenças de deviances das amostras bootstrap com a diferença de deviances inicial. Os resíduos utilizados são os resíduos simples, de Pearson e de Pearson padronizados. A aplicação da técnica é realizada através de dois conjuntos de dados de experimentos agronômicos, em que, no primeiro, a variável resposta foi o tempo até a murcha de um cultivar de linho susceptível ao patógeno Fusarium oxysporum e, no segundo, a variável resposta é o tempo até o inseto Podysus nigrispinus atingir a fase adulta. O método bootstrap indicou evidência de que o modelo logístico é o mais adequado para ajustar os dados do experimento com linho. Já no caso do experimento com insetos, o método indicou o modelo de Cox como o mais adequado aos dados e o resíduo de Pearson e Pearson padronizado, em ambos os casos, foram os que forneceram uma maior indicação para a escolha dos modelos em questão. 


\title{
THE UTILIZATION OF THE BOOTSTRAP METHOD TO CHOOSE BETWEEN THE COX AND THE LOGISTIC MODELS FOR INTERVAL-CENSORED DATA
}

\author{
Author: JEANETE ALVES MOREIRA \\ Adviser: Prof. Dr. JOSÉ EDUARDO CORRENTE
}

SUMMARY

In many scientific works, researchers are interested in identifying variables or factors that influence the time of occurrence of certain events, which is generally known as failure time. However, it's not always possible to observe the exact failure time knowing only the interval in which failure occurred. Such data are known as grouped data or interval-censored data and present tied observations. When the number of ties is small, analysis of such data can be made by fitting the Cox Model (Cox, 1972) considering approximations for partial likelihood. In case there are many ties, the time must be considered as discreet and the probability of occurrence of the event must be modeled in a certain interval, since it did not take place in the immediately preceding interval. This can be done by considering the response variable as a binary variable that indicates failure and by fitting the Cox 
xiv

model for grouped data or the logistic model through generalized linear models with complementary log-log and logit link functions, respectively. After fitting the models, it is necessary to decide which of them is more adequate for the experimental data. To that end, some model selection techniques are available in the literature, such as the Akaike Information Criterion (Akaike, 1973) and the Score Tests proposed by Colosimo et al. (2000), among others. This work proposes a new methodology to select between the Cox and logistic models for interval-censored data using the bootstrap method for the residues. This is done by extracting the residues from the fit of the proposed models and by calculating the deviance difference between the fitted models. After that, new observations are recomposed from the bootstrap residues and new deviance differences are calculated. A histogram for such values is then obtained and an empirical significance level is proposed by comparing the differences deviance values in the bootstrap samples with the deviance difference in the initial fit. The residues used are the simple residues, Pearson and standardized Pearson residues. The application of the technique was conducted through two data sets concerning agronomic experiments, in the first of which the response variable was the time until the blight of a flax cultivar susceptible to the pathogen Fusarium oxysporum and, in the second, the response variable was the time until the insect Podysus nigrispinus reached its adult phase. The bootstrap method indicated the evidence that the logistic model is more adequate to fit data for the experiment concerning flax. However, in the experiment concerning insects, the method indicated the Cox model as more adequate for the data, and the Pearson and standardized Pearson residue, in both cases, provided a greater indication for the choice of the considered models. 


\section{INTRODUÇÃO}

Em muitas pesquisas científicas, nas mais diversas áreas do conhecimento, o interesse dos pesquisadores está em identificar fatores que expliquem o tempo até a ocorrência de um determinado evento como, por exemplo, o tempo até a falha de um componente, o tempo até a morte de um indivíduo, o tempo até a murcha de uma planta etc. Esse tempo é referido na literatura como tempo de vida ou tempo de falha e, uma característica importante nesses dados é a possibilidade de serem censurados, ou seja, por algum motivo não se observou o evento de interesse em alguns indivíduos, no período estudado. Nem sempre, porém, é possível observar o tempo exato de ocorrência do evento, conhecendo-se somente o intervalo em que o mesmo ocorreu. Dados desse tipo são conhecidos como agrupados ou de sobrevivência com censura intervalar e apresentam observações empatadas.

A análise de tais dados pode ser feita, no caso de um número pequeno de empates, pelo ajuste do modelo de Cox (Cox, 1972), através da função de verossimilhança parcial exata ou considerando-se aproximações, tais como as propostas por Breslow (1972, 1974), Peto (1972), Efron (1977) e Farewell e Prentice (1980). No caso de um número grande de empates considera-se o tempo como discreto e modela-se a probabilidade de ocorrência do evento num determinado intervalo, dado que ele não ocorreu no intervalo imediatamente anterior. Isso pode ser feito utilizando o modelo de riscos proporcionais de Cox para dados agrupados (Prentice \& Gloeckler, 1978) ou o modelo logístico (Lawless, 1982). O ajuste dos modelos para tempos discretos na presença de censura intervalar pode ser realizado através dos modelos lineares generalizados (Nelder \& Weddeburn, 1972). 
Após o ajuste do modelo, existe o interesse em saber qual deles melhor explica os dados experimentais. Com essa finalidade, Chalita (1997) propôs dois testes escores a partir de uma distribuição mais geral, a família de transformação assimétrica de Aranda-Ordaz (1981), que tem como casos particulares as transformações logit (modelo logístico) e complemento log-log (modelo de riscos proporcionais de Cox). Os testes discriminam os modelos de Cox e logístico.

Este trabalho propõe uma nova metodologia para escolher entre os modelos de Cox e logístico para dados com censura intervalar. Esta metodologia é baseada no ajuste destes dois modelos e, através da simulação bootstrap dos resíduos, novas observações bootstrap são produzidas e novos ajustes dos modelos são feitos.

A decisão de escolha entre os modelos será tomada a partir da análise da distribuição empírica da diferença de deviances e do cálculo de um nível de significância empírico, baseado na distância entre as diferenças de deviances obtidas pelos ajustes dos modelos com base nas observações bootstrap e com os dados originais.

Como aplicação da metodologia serão utilizados dois conjuntos de dados de experimentos agronômicos, em que, no primeiro, a variável resposta é o tempo até a murcha de um cultivar de linho susceptível ao patógeno Fusarium oxysporum; no segundo, a variável resposta é o tempo até o inseto Podisus nigrispinus atingir a fase adulta. Ambos os conjuntos de dados apresentam alta proporção de empates, sendo necessário, portanto, a utilização dos modelos discretos. Os objetivos específicos deste trabalho são:

(i) ajustar os modelos logístico e de Cox para os dados dos dois experimentos em estudo, usando a teoria dos modelos lineares generalizados;

(ii) desenvolver programas computacionais para a reamostragem bootstrap dos três tipos de resíduos que serão considerados;

(iii) identificar os fatores que influenciaram no tempo de vida para cada experimento realizado;

(iv) analisar os resultados obtidos para cada tipo de resíduo considerado; 
(v) discriminar entre os modelos de Cox e logístico;

(vi) avaliar a técnica bootstrap proposta neste trabalho. 


\section{REVISÃO DE LITERATURA}

\subsection{Análise de sobrevivência}

A Análise de sobrevivência é uma das áreas da estatística na qual são desenvolvidos métodos para analisar dados provenientes de variáveis aleatórias tomando valores positivos. Essas variáveis correspondem ao tempo de ocorrência de um evento de interesse, tais como o tempo até a morte ou cura de um indivíduo, tempo até a falha de um componente eletrônico, dentre outros. Estes métodos foram originalmente desenvolvidos para estudos de mortalidade, explicando, portanto, o nome sobrevivência que, segundo Allison (1995), é um tanto inadequado por levar a uma visão restrita suas potenciais aplicações.

Existem duas características bastante importantes nos dados de sobrevivência. Uma, diz respeito à distribuição dos dados que, geralmente, é assimétrica à direita e a outra é a presença de censuras, que ocorre quando não é possível observar a resposta de algumas unidades que deverão ser incluídas na análise.

O principal interesse da área de análise de sobrevivência está na estimação da probabilidade de um indivíduo sobreviver até o tempo $t$, conhecida como função de sobrevivência e a razão instantânea de falha no tempo $t$, dado que ele sobreviveu até $t$, chamada de função de risco.

Dentre as técnicas utilizadas para estimar-se a função de sobrevivência destacam-se as paramétricas e as não-paramétricas. As técnicas não paramétricas são apenas descritivas e o estimador mais utilizado para a função de sobrevivência é o produto-limite de Kaplan-Meier (Kaplan \& Meier, 1958), o qual é utilizado quando 
se conhece o tempo exato de falha, embora também possa ser utilizado para um número pequeno de empates. Um outro estimador não-paramétrico para a função de sobrevivência é a tabela de vida ou o estimador atuarial, que considera os dados agrupados, ou seja, são conhecidos apenas os intervalos em que as falhas ou censura ocorreram.

Estas técnicas não levam em consideração as covariáveis relacionadas com o tempo de sobrevivência. Para considerar estas covariáveis devem-se utilizar os modelos paramétricos ou teste de vida acelerado para os quais se supõe uma distribuição de probabilidade conhecida para os tempos e o modelo semi-paramétrico de Cox (1972), para o qual não é necessário supor distribuição para a variável tempo.

$\mathrm{O}$ tempo de sobrevivência $T$ tem função densidade de probabilidade, $f(t)$, definida como a probabilidade instantânea de o indivíduo falhar no intervalo $[t ; t+\Delta t]$ por unidade de tempo, que pode ser expressa por

$$
\begin{aligned}
f(t) & =\lim _{\Delta t \rightarrow 0^{+}} \frac{P(\text { um indivíduo falhar em }[t ; t+\Delta t])}{\Delta t} \\
& =\lim _{\Delta t \rightarrow 0^{+}} \frac{P(t \leq T \leq t+\Delta t)}{\Delta t}=\frac{d F(t)}{d t} .
\end{aligned}
$$

em que $F(t)=P(T \leq t)$ é a função de distribuição de $T$. Tem-se ainda que, se $f(t)$ define uma verdadeira função de densidade de probabilidade, então:

$$
f(t) \geq 0 \quad e \quad \int_{0}^{\infty} f(t) d t=1
$$

A função de sobrevivência, denotada por $S(t)$, representa a probabilidade de o indivíduo não falhar até um certo tempo $t$, isto é,

$$
S(t)=P(T \geq t)=1-F(t)
$$

e é uma função monótona decrescente que satisfaz a:

$$
S(0)=1 \quad e \quad \lim _{t \rightarrow \infty} S(t)=0 .
$$

A função $S(t)$ é também conhecida como razão de sobrevivência acumulada e sua representação gráfica é chamada de curva de sobrevivência, que pode ser 
usada para encontrar qualquer percentil de interesse e, também, como um primeiro elemento de comparação entre dois ou mais tratamentos.

A função risco, representada por $h(t)$, especifica a taxa de falha instantânea no tempo $t$ e é dada por:

$$
\begin{aligned}
h(t) & =\lim _{\Delta t \rightarrow 0^{+}} \frac{P(t \leq T \leq t+\Delta t / T \geq t)}{\Delta t} \\
& =\lim _{\Delta t \rightarrow 0^{+}} \frac{P(t \leq T \leq t+\Delta t, T \geq t)}{\Delta t P(T \geq t)} . \\
& =\lim _{\Delta t \rightarrow 0^{+}} \frac{P(t \leq T \leq t+\Delta t)}{\Delta t P(T \geq t)},
\end{aligned}
$$

pois $[t \leq T \leq t+\Delta t] \subset[T \geq t]$. Então,

$$
h(t)=\lim _{\Delta t \rightarrow 0^{+}} \frac{F(t+\Delta t)-F(t)}{\Delta t} \frac{1}{S(t)}=\frac{f(t)}{S(t)}=\frac{f(t)}{1-F(t)} .
$$

As funções (1), (2) e (3) são matematicamente equivalentes, ou seja, dada uma delas as outras podem ser obtidas facilmente.

\section{Relações entre as funções $f(t), S(t)$ e $h(t)$}

1. A função de risco instantânea pode ser dada por:

$$
h(t)=\frac{f(t)}{S(t)} .
$$

2. A função de densidade de $T$ pode ser dada por:

$$
f(t)=\frac{d F(t)}{d t}=\frac{d[1-S(t)]}{d t}=-S^{\prime}(t) .
$$

3. Substituindo-se a equação (5) em (4), tem-se que:

$$
h(t)=\frac{-S^{\prime}(t)}{S(t)}=\frac{-d \log S(t)}{d t} .
$$


4. Integrando-se (6) no intervalo $[0 ; t]$ e usando $S(0)=1$, pode ser visto que:

$$
-\int_{0}^{t} h(x) d x=\log S(t)
$$

ou,

$$
H(t)=-\log S(t)
$$

ou ainda,

$$
S(t)=\exp [-H(t)]=\exp \left[-\int_{0}^{t} h(x) d x\right]
$$

5. Das equações (4) e (7), obtém-se:

$$
f(t)=h(t) \exp [-H(t)]
$$

O modelo de riscos proporcionais foi proposto por Cox (1972), sendo um dos modelos mais utilizados na prática pela sua flexibilidade, ou seja, não requer que se escolha alguma distribuição de probabilidade para os tempos de falha, além de levar em consideração as covariáveis relacionadas com esse tempo. Este modelo supõe independência entre os tempos observados e modela a função de risco através da função:

$$
h\left(t \mid \mathbf{x}_{l}\right)=h_{0}(t) \exp \left(\boldsymbol{\beta}^{\prime} \mathbf{x}_{l}\right)
$$

em que:

- $h_{0}(t)$ é a função risco de base (taxa de risco para $x_{l}=0$ );

- $\boldsymbol{\beta}$ é o vetor de dimensão $p \times 1$ de parâmetros desconhecidos;

- $\mathbf{x}_{l}$ é o vetor de dimensão $p \times 1$ de covariáveis observadas para o $l$-ésimo indivíduo. 
O modelo dado por (8) é denominado modelo de riscos proporcionais pelo fato de a razão entre as taxas de falhas para dois indivíduos ser constante no tempo, ou seja, tomando-se a razão de riscos para dois indivíduos $l$ e $j$ e aplicando-se a equação (8), obtém-se o resultado abaixo, que não depende do tempo:

$$
\frac{h_{l}\left(t \mid x_{l}\right)}{h_{j}\left(t \mid x_{l}\right)}=\frac{h_{0}(t) \exp \left(\beta^{\prime} x_{l}\right)}{h_{0}(t) \exp \left(\beta^{\prime} x_{j}\right)}=\exp \left(\beta^{\prime} x_{l}-\beta^{\prime} x_{j}\right) .
$$

Devido a presença do componente não-paramétrico $h_{0}\left(t \mid \mathbf{x}_{l}\right)$ no modelo, o método da máxima verossimilhança usual não é apropriado para estimar os parâmetros. Desse modo, Cox(1975) formalizou o método da máxima verossimilhança parcial que consiste em condicionar a função de verossimilhança nos tempos de ocorrência do evento de modo a eliminar a função de perturbação $h_{0}\left(t \mid \mathbf{x}_{l}\right)$.

Ocorre, porém, que quando acontecem empates não se pode utilizar a função de verossimilhança parcial exata e, nesse caso, existem métodos alternativos tais como os apresentados por Breslow (1974) e Efron (1977).

Estes autores propuseram aproximações para a função de verossimilhança parcial e estas encontram-se implementadas em vários softwares estatísticos. Quando o número de empates é pequeno ambas as aproximações fornecem valores próximos, todavia, a aproximação de Efron (1977) apresenta resultados mais próximos daqueles encontrados pela forma exata. Autores como Kalbfleish \& Prentice (1980), Lawless (1982), Cox \& Oakes (1974), Collett (1994), Allisson (1995) e Chalita (1997) indicam que, no caso de muitos empates, deve-se considerar o tempo como discreto para modelar a probabilidade de o indivíduo falhar num determinado intervalo, dado que ele sobreviveu até o intervalo anterior, através dos modelos de riscos proporcionais de Cox para dados com censura intervalar ou o modelo logístico.

Kalbfleish \& Prentice (1973) desenvolveram um modelo discreto para dados agrupados a partir do modelo de Cox, apresentando estimativas da função de sobrevivência para dados contínuos e discretos além de propor uma generalização do teste log-rank para comparação de várias curvas de sobrevivência. Enquanto Prentice \& Gloeckler (1978) ajustaram o modelo de Cox para dados de câncer de mama 
agrupados e apresentaram as propriedades assintóticas da função de verossimilhança para estimação do coeficiente de regressão e da função de sobrevivência. Nos estudos de Whitehead (1989) encontra-se um ajuste do modelo de riscos proporcionais de Cox a dados com censura intervalar através da utilização do modelo linear generalizado, considerando que a função de ligação é a complemento log-log e que a variável resposta é a indicadora de censura, que é binária.

Uma metodologia mais ampla para usar o modelo de riscos proporcionais na análise de dados com censura intervalar foi desenvolvida por Finkelstein (1986). Essa metodologia permite incorporar observações que, por algum motivo, se ausentaram do estudo em um determinado período ao acompanhamento realizado pelo pesquisador e depois voltem a ser incorporadas ao ensaio. Por exemplo, um indivíduo que foi monitorado semanalmente pode faltar por algumas semanas e depois retornar ao monitoramento. Neste caso podem ocorrer censuras em intervalos sobrepostos ou não disjuntos e os métodos utilizados por Prentice e Gloeckler (1978) não poderiam ser aplicados. A autora também apresenta um teste para verificar se há diferença entre as curvas de sobrevivência, mostrando a relação entre a estatística do teste e a estatística usual utilizada no teste log-rank para tempos exatos e censurados à direita.

O modelo logístico foi ajustado por Thompson (1977) a dados de remissão de leucemia agrupados em intervalos de tempo, considerando a censura uniforme no intervalo. Este modelo recai no modelo de Cox considerando tempos como contínuos quando os comprimentos dos intervalos aproximam-se de zero. Lawless (1982) discutiu com detalhes o caso de dados agrupados, ajustando o modelo de Cox e o logístico.

Collett (1994) trabalhou com dados de sobrevivência com censura intervalar mostrando três formas diferentes de análise, utilizando dados de recorrência de úlcera apresentados por (Whitehead, 1989). As formas consideradas para análise foram: sem considerar censura intervalar (considerando o tempo de recorrência como contínuo); sem considerar o tempo no qual uma recorrência foi detectada e con- 
siderando censura intervalar juntamente com o período em que houve a recorrência. A conclusão do autor é que a terceira forma utilizada para ajustar esse conjunto de dados é, geralmente, a forma mais eficiente de análise, embora o resultado não fosse tão diferente da análise que assume o tempo como contínuo quando o número de intervalos não foi tão pequeno e o comprimento destes não foi grande.

Mais recentemente, Chalita (1997) fez comparações entre as aproximações da função de verossimilhança parcial para dados empatados e os modelos de Cox e logístico para tempos discretos. Para tal propósito, a autora fez simulações para os dados de tempo de falha utilizando a distribuição de Weibull, variando a proporção de censura e o tamanho da a mostra, empregando 5, 10, 20 e 30 intervalos. Considerando o tempo como contínuo, utilizou o limite superior de cada classe e no caso discreto foi considerado o número de falhas e o número de indivíduos sob risco no intervalo. As conclusões obtidas mostraram que, quando o tempo é considerado como contínuo, a forma exata comporta-se melhor seguida pelas aproximações de Efron (1977) e Breslow (1974), independente da variação do número de intervalos, da proporção de censura, dos parâmetros e se o vetor de covariáveis é binário ou contínuo.

Para o tamanho de amostra $n=20$, as diferenças entre os ajustes considerando-se o tempo como discreto e contínuo com aproximações são mais evidentes e, à medida que se aumenta o número de intervalos, o erro quadrático e o vício diminuem para os modelos contínuos e aumentam para os discretos. Isso porque a proporção de empates diminui e no caso discreto aumenta o número de parâmetros a serem estimados nos modelos. Com relação aos modelos para tempo discreto, o modelo de Cox ajustou-se melhor do que o logístico, embora esta conclusão possa ser explicada pelo fato de ter sido usada a distribuição de Weibull para gerar os dados, cujos riscos são proporcionais.

As Tabelas 1 e 2 mostram algumas sugestões empíricas que foram apresentadas por Chalita (1997) com relação ao uso dos modelos considerando os tempos discreto e contínuo com aproximações e levando-se em conta a proporção de 
empates.

Tabela 1. Relação entre proporções de empates (pe) e o modelo a ser utilizado, para amostras de tamanho 20 e 50 .

\begin{tabular}{c|c}
\hline pe(\%) & Modelos \\
\hline$<20$ & Devem-se usar modelos para tempo contínuo com aproximações \\
20 a 30 & Podem-se usar modelos para tempo contínuo com aproximações \\
$>30$ & Devem-se usar modelos para tempo discreto \\
\hline
\end{tabular}

Tabela 2. Relação entre proporções de empates (pe) e o modelo a ser utilizado, para amostras de tamanho 100 e 200.

\begin{tabular}{c|c}
\hline pe(\%) & Modelos \\
\hline$<20$ & Devem-se usar modelos para tempo contínuo com aproximações \\
20 a 25 & Podem-se usar modelos para tempo contínuo com aproximações \\
$>25$ & Devem-se usar modelos para tempo discreto \\
\hline
\end{tabular}

Fay (1999) apresentou um modelo geral para desenvolver um teste escore a fim de testar os parâmetros envolvidos nos modelos de riscos proporcionais de Cox, logístico e de chances proporcionais para dados com censura intervalar que tem como casos particulares os modelos apresentados por Finkelstein (1986) e Sun (1996). $\mathrm{O}$ teste proposto pelo autor considerou somente comparações entre $k$ tratamentos e mostrou a equivalência entre a forma da estatística escore para o teste log-rank ponderado e a forma utilizada nos testes de permutação. 


\subsection{Modelos lineares generalizados}

Os modelos lineares generalizados (MLG) foram desenvolvidos por Nelder \& Wedderburn (1972) e constituem uma extensão dos modelos lineares clássicos de Gauss-Markov.

A definição de modelos lineares generalizados envolve três componentes:

1. Componente aleatório: representado pelas variáveis aleatórias independentes $Y_{1}, Y_{2}, \cdots, Y_{n}$ pertencentes à família exponencial na forma:

$$
f_{Y}\left(y_{i}, \theta, \phi\right)=\exp \left\{\frac{1}{a(\phi)}\left[y_{i} \theta-b(\theta)\right]+c\left(y_{i} ; \phi\right)\right\}
$$

em que $a(),. b($.$) e c($.$) são funções conhecidas, sendo \mu_{i}=E\left(Y_{i}\right)=b^{\prime}(\theta)$ e $V\left(Y_{i}\right)=a(\phi) b^{\prime \prime}\left(\theta_{i}\right)=a(\phi) V(\mu), V(\mu)$ é chamada de função de variância e, em geral, $a(\phi)=\phi / W$, em que $\phi$ é o parâmetro de dispersão e $W$ são os pesos a priori. Quando se conhece $\phi,(9)$ pertence à família exponencial na forma canônica a um parâmetro e $\theta$ é chamado de parâmetro canônico ou natural.

2. Componente sistemático: um preditor linear dado por:

$$
\eta_{i}=\sum_{j=1}^{\ell} \beta_{j} x_{i j} \quad \text { ou } \quad \eta=X \boldsymbol{\beta}
$$

em que $X$ é uma matriz $n \times \ell$ do delineamento (covariáveis ou variáveis binárias) e $\boldsymbol{\beta}$ é um vetor $\ell \times 1$ de parâmetros desconhecidos.

3. Uma função de ligação $g($.$) monótona e diferenciável que relaciona o compo-$ nente aleatório com o componente sistemático:

$$
g\left(\mu_{i}\right)=\eta_{i}=\sum_{j=1}^{\ell} \beta_{j} x_{i j}, \quad i=1,2 \ldots, n
$$


Quando $g\left(\mu_{i}\right)=\theta_{i}$, a função de ligação é chamada de função de ligação canônica ou natural. As funções de ligação mais comuns para dados binomiais são a logit, probit e complemento log-log.

Os estimadores de máxima verossimilhança para os parâmetros do modelo, $\hat{\boldsymbol{\beta}}$, são obtidos pelo método escore de Fisher, implementado através do algoritmo de mínimos quadrados reponderados iterativamente, IRLS (McCullagh \& Nelder, 1989).

Uma medida de discrepância chamada deviance foi proposta por Nelder \& Wedderburn (1972), sendo a análise de deviance uma generalização da análise de variância. Essa medida é dada por

$$
D(\mathbf{y}, \hat{\boldsymbol{\mu}})=2 l(\mathbf{y}, \mathbf{y})-2 l(\hat{\boldsymbol{\mu}}, \mathbf{y})
$$

em que

$l(\mathbf{y}, \mathbf{y})$ é o logaritmo da função de verossimilhança para o modelo saturado, e

$l(\hat{\boldsymbol{\mu}}, \mathbf{y})$ é o logaritmo da função de verossimilhança para o modelo sob pesquisa, servindo para avaliar a falta de ajuste de um modelo. No caso de modelos encaixados, a diferença de deviances mede o efeito de fatores, covariáveis e suas possíveis interações.

Cordeiro (1986) e Demétrio (1993) são duas referências em português que mostram detalhes do processo de estimação dos parâmetros e dão ênfase ao uso do software GLIM (Generalized Linear Iteractive Modelling). Dobson (1990) apresenta uma introdução aos modelos lineares generalizados de forma bastante didática sendo, portanto, recomendada para uma primeira leitura.

Um caso particular dos MLG's são os dados de proporções que podem ser analisados através da distribuição binomial. Collett (1991) descreveu detalhadamente os modelos para dados binários e binomiais apresentando várias aplicações 
nos ensaios de Entomologia, em estudo de coorte, caso-controle e ensaios de doseresposta.

Para se modelarem dados binomiais através dos modelos lineares generalizados considerem-se as variáveis aleatórias $Y_{1}, Y_{2}, \cdots, Y_{n}$ independentes, representando o número de sucessos em amostras de tamanho $m_{i}$, com probabilidade de sucesso $\pi_{i}, i=1,2, \cdots, n$. Se $Y_{i} \sim b\left(m_{i}, \pi_{i}\right)$ então, $E\left(Y_{i}\right)=\mu_{i}=m_{i} \pi_{i}$ e $V\left(Y_{i}\right)=m_{i} \pi_{i}\left(1-\pi_{i}\right)$, podendo-se modelar $\pi_{i}$ em termos das covariáveis ou fatores $X_{i}^{\prime} s$ como $g\left(\pi_{i}\right)=\boldsymbol{\beta}^{\prime} \mathbf{x}_{\mathbf{i}}$, onde $g($.) é uma função de ligação apropriada e $\boldsymbol{\beta}$ é o vetor de parâmetros desconhecidos. As funções de ligação utilizadas neste trabalho serão logit (modelo logístico) e complemento log-log (modelo de Cox).

\subsection{O método bootstrap}

Nas duas últimas décadas, juntamente com os computadores de alta velocidade com grandes capacidades de armazenamento de dados a custos mais acessíveis, vem sendo cada vez mais utilizada uma metodologia para análise estatística conhecida como computacionalmente intensiva. Esses métodos começaram a se tornar ferramentas bastante úteis e alternativas para os métodos estatísticos tradicionais, pois visam substituir as complexidades analíticas ou uso de aproximações assintóticas para determinados problemas. Entre esses métodos, podem-se destacar o Jackknife e o bootstrap, apresentados por Efron (1979).

Algumas condições de regularidade sob as quais esse método é consistente foram discutidas por Bickel \& Freedman (1981). Hall (1992) abordou as propriedades teóricas do método, enquanto os conceitos básicos e muitas aplicações práticas do método it bootstrap podem ser encontrados em Efron \& Tibishirani(1993) e Davison \& Hinkley (1997).

O bootstrap é um método que pode ser facilmente implementado tanto de forma não-paramétrica quanto paramétrica, dependendo do conhecimento do problema. No caso não-paramétrico, o método bootstrap reamostra os dados um 
número $\mathbf{B}$ de vezes com reposição, em que os valores são escolhidos segundo uma função de distribuição empírica estimada, tendo em vista que, em geral, não se conhece a distribuição subjacente aos dados. No caso paramétrico, quando se tem informação suficiente sobre a forma da distribuição dos dados, a amostra bootstrap é formada realizando-se a amostragem diretamente nesta distribuição com os parâmetros desconhecidos substituídos por estimativas paramétricas. A distribuição da estatística de interesse aplicada aos valores da amostra bootstrap, condicional aos dados observados, é definida como a distribuição bootstrap desta estatística.

Considerando-se $Y_{1}, \ldots, Y_{n}$ uma amostra aleatória de tamanho $n$ com distribuição de probabilidade desconhecida $F$ que depende de um parâmetro $\theta$, e sejam y $=\left(y_{1}, y_{2}, \ldots, y_{n}\right)$ os valores observados. Como a função $F$ é desconhecida, pode-se estimá-la pela função de distribuição empírica, baseado na amostra de tamanho $n$ que é dada por:

$$
\hat{F}(y)=\frac{\#\left(y_{j} \leq y\right)}{n}
$$

A função $\hat{F}$ assume valores $1 / n$ para cada valor da amostra $y_{i}, i=1, \ldots, n$.

Supondo-se agora que se queira estimar o parâmetro $\theta$ que depende da distribuição $F$, isto é, supondo-se que $\theta=t(F)$ baseado em Y. Um estimador de $\theta$ é $\hat{\theta}=s(\mathbf{Y})$ e é preciso saber qual a precisão deste estimador. Para isto, utiliza-se o método bootstrap, que retira amostras bootstrap com reposição $y_{1}^{*}, \ldots, y_{n}^{*}$ utilizando a função de distribuição empírica estimada $\hat{F}$. Assim, para a amostra bootstrap $\mathbf{y}^{*}=\left(y_{1}^{*}, \ldots, y_{n}^{*}\right)$, calcula-se

$$
\hat{\theta}^{*}=s\left(\mathbf{y}^{*}\right) .
$$

Um diagrama esquemático para o método bootstrap é dado pela Tabela 3.

Ao se obter um grande número de replicações bootstrap de $y_{1}, \ldots, y_{n}$, obtem-se a distribuição empírica de $\hat{\theta}^{*}$, podendo-se calcular medidas de posição, dispersão, intervalos de confiança, dentre outras, de modo a analisar a precisão do estimador obtido inicialmente. 
Tabela 3. Diagrama esquemático do método bootstrap

\begin{tabular}{|c|c|c|c|c|}
\hline \multicolumn{2}{|c|}{ Mundo Real } & & \multicolumn{2}{|c|}{ Mundo Boostrap } \\
\hline Distribuição de & Amostra & & & \\
\hline Probabilidade & Aleatória & & Distribuição & Amostra \\
\hline Desconhecida & Observada & & Empírica & Bootstrap \\
\hline$F \longrightarrow$ & $\mathbf{y}=\left(y_{1}, \ldots, y_{n}\right)$ & $\Longrightarrow$ & $\hat{F} \longrightarrow$ & $\mathbf{y}=\left(y_{1}^{*}, \ldots, y_{n}^{*}\right)$ \\
\hline & $\downarrow$ & & & $\downarrow$ \\
\hline & $\hat{\boldsymbol{\theta}}=s(\mathbf{y})$ & & & $\hat{\theta}^{*}=s\left(\mathbf{y}^{*}\right)$ \\
\hline & Estatística & & & Replicação \\
\hline & de Interesse & & & Bootstrap \\
\hline
\end{tabular}

Quando se tem informações suficientes sobre $F$, o estimador bootstrap $\hat{\theta}^{*}$ de $\theta$ pode ser obtido da mesma forma que o já descrito anteriormente, apenas levando-se em conta a verdadeira distribuição subjacente aos dados.

Dentre as várias aplicações do método bootstrap, existe o interesse particular nos modelos de regressão. Freedman (1981) trabalhou com o método bootstrap em modelos de regressão e correlação mostrando a validade de sua aproximação para a distribuição dos estimadores dos parâmetros do modelo utiliżando o método de mínimos quadrados. Esse assunto foi abordado por Hinkley (1988), Efron \& Tibishirani (1993), Silva (1995) e Davison \& Hinkley (1997) dentre outros. Silva (1995), por sua vez, apresentou uma descrição detalhada sobre o método bootstrap aplicado à regressão múltipla e mostrou a eficiência do método em um problema de regressão com restrição nos parâmetros utilizando dados de um experimento químico.

Para o modelo de regressão, $\mathbf{Y}=\mathbf{X} \boldsymbol{\beta}+\mathbf{e}$, em que $\mathbf{Y}$ é o vetor de respostas, $\mathbf{X}$ é a matriz de covariáveis, $\boldsymbol{\beta}$ é o vetor de parâmetros desconhecidos e e é o vetor de erros independentes e identicamente distribuídos, com distribuição 
$\mathrm{F}$, média zero e variância $\sigma^{2}$, o plano de reamostragem pode ser feito através dos resíduos ou dos pares de observações (Davison \& Hinkley, 1997).

A abordagem do método bootstrap também pode ser feita para os modelos lineares generalizados e, nesse caso, a reamostragem dos resíduos é realizada de forma análoga aos modelos lineares ordinários. Alguns dos resíduos discutidos na literatura usados para esses tịpos de modelos, são: os resíduos de Pearson, os resíduos de Pearson padronizados, os resíduos componentes da deviance, os resíduos componentes da deviance padronizados e os resíduos padronizados na escala do preditor linear.

Moulton \& Zeger (1989) utilizaram reamostragem dos vetores de observações com reposição em uma análise de medidas repetidas no contexto de modelos lineares generalizados seguindo a mesma metodologia utilizada em modelos lineares ordinários. Já em Moulton \& Zeger (1991), foi sugerido o uso de reamostragem dos resíduos de Pearson padronizados obtidos do ajuste de um modelo linear generalizado.

\subsection{Seleção de modelos}

Ao se analisar um conjunto de dados, um modelo matemático é sempre pressuposto e, através do ajuste desse modelo e de testes apropriados, é possível verificar se existem efeitos significativos para as covariáveis envolvidas.

Em praticamente todos os softwares estatísticos, é possível fazer ajuste de modelos incluindo todos os efeitos de uma só vez ou um efeito por vez, verificando a qualidade do ajuste. Neste caso, diz-se que o ajuste do modelo é feito através de modelos encaixados e, uma medida utilizada para verificar o efeito de cada fator, é a diferença de deviances, como já citada na Seção 2.2. Quando os ajustes são feitos baseados em diferentes suposições de modelos, tem-se o caso de ajuste de modelos não encaixados.

O problema da seleção de modelos não encaixados foi apresentada em 
Cox (1962), obtendo resultados assintóticos para testar duas hipóteses não encaixadas, considerando os modelos $M_{f}$ como hipótese nula e $M_{g}$ como a hipótese alternativa, baseado na estatística da razão de verossimilhança, dada por:

$$
T_{f}=\left[L_{f}(\hat{\alpha})-L_{g}(\hat{\beta})\right]-E_{\hat{\alpha}}\left[L_{f}(\hat{\alpha})-L_{g}(\hat{\beta})\right]
$$

em que $L_{f}(\alpha)$ é o logaritmo da função de verossimilhança de $\alpha$ sob o modelo $M_{f}$ e $\left.E_{\hat{\alpha}}\right]$ é o valor esperado de $L_{f}(\alpha)$ com relação a a $M_{f}$ para $\alpha=\hat{\alpha}$ (em que $\hat{\alpha}$ é o estimador de máxima verossimilhança de $\alpha$ ). O autor mostrou que esta estatística é assintoticamente normal sob o modelo $M_{f}$.

Uma abordagem para a escolha de dois modelos de regressão não lineares foi discutida por Williams (1970). Para selecionar qual desses modelos melhor se ajusta aos dados, o autor obteve distribuições para a estatística do teste através da simulação de cada um dos modelos ajustados, usando a especificação paramétrica do modelo e reajustando cada modelo para o conjunto de dados simulados. Em seu trabalho, foi sugerido também substituir o cálculo teórico de $T_{f}$ e $T_{g}, \operatorname{com} T_{g}$ definido analogamente a $T_{f}$ no parágrafo acima, pela simulação da razão de verossimilhança sob cada modelo estimado.

A comparação de modelos lineares não encaixados utilizando intervalos de confiança aproximados para a diferença no erro quadrático médio de previsão foi apresentada em Efron (1984). O autor mostrou que essa abordagem é relativamente próxima ao teste de Hotelling para comparar dois modelos de regressão linear simples. Os intervalos foram construídos através do método bootstrap paramétrico aplicado ao estimador $C_{p}$ de Mallows's ${ }^{1}$, citado por Efron(1984), da diferença entre os erros quadráticos médios.

Tomando como base o trabalho de Williams (1970), Hinde (1992) ${ }^{2}$ substituiu a simulação paramétrica pela simulação bootstrap. Este procedimento tem a vantagem de a simulação bootstrap não depender das especificações do mo-

\footnotetext{
${ }^{1}$ MALLOWS, C. L. Some comments on $C_{p}$. Technometrics, v.15, p.661-675, 1973.

${ }^{2}$ HINDE, J. Choosing between non-nested models: a simulation aproach. 1992. (Trabalho não publicado).
} 
delo, apenas envolvendo reamostragem de um conjunto finito de observações. O procedimento consiste no ajuste de dois modelos, $M_{1}$ e $M_{2}$, que podem ter diferentes especificações de erros e funções de ligação. Isso feito, retiram-se amostras bootstrap, reamostrando-se os resíduos de Pearson padronizados para o modelo ajustado $M_{1}$ e reajustando-se os dois modelos para cada amostra bootstrap. O mesmo foi feito considerando a reamostragem dos resíduos para o modelo $M_{2}$. As diferenças de $d e-$ viances entre os modelos foram utilizadas para construir uma distribuição empírica e a comparação desta distribuição com a diferença de deviances indica a preferência de um modelo em relação ao outro, ou que não há diferença entre os dois modelos ou ainda que nenhum dos modelos se ajustou bem aos dados.

Shao (1996) propôs um método de seleção de variáveis baseado no bootstrap, enfatizando as boas propriedades do método e citando duas fortes razões para seu uso que são: i) a precisão dos procedimentos utilizados pelo bootstrap no contexto de regressão linear ser maior do que em outros métodos; ii) o procedimento de seleção bootstrap desenvolvido para o caso de regressão linear pode ser estendido, sem qualquer teoria adicional, para problemas mais complicados tais como, modelos de regressão não linear, modelos lineares generalizados e modelos auto-regressivos.

$\mathrm{O}$ autor considerou duas maneiras de gerar observações bootstrap que são a reamostragem através dos resíduos e dos pares de observações $(x, y)$, mas incorporando uma modificação no tamanho da amostra bootstrap com a finalidade de tornar o procedimento de seleção de modelos mais consistente. $\mathrm{O}$ critério de seleção de modelos foi baseado no erro de predição agregado bootstrap, sendo escolhido como melhor modelo aquele que minimiza este erro.

Colosimo et al. (2000) desenvolveu testes escores para discriminar entre os dois modelos discretos estudados, modelos de riscos proporcionais de Cox e logístico, a partir da família assimétrica de Aranda-Ordaz (1981), dada por:

$$
V_{\lambda}\left(p_{i}\left(\mathbf{x}_{l}\right)\right)= \begin{cases}\ln \left(\frac{\left[1-p_{i}\left(\mathbf{x}_{l}\right)\right]^{-\lambda}-1}{\lambda}\right) & \text { se } \lambda \neq 0 \\ \ln \left(-\ln \left(1-p_{i}\left(\mathbf{x}_{l}\right)\right)\right) & \text { se } \lambda=0\end{cases}
$$


em que $p_{i}\left(\mathbf{x}_{l}\right)$ é a probabilidade do $l$-ésimo indivíduo falhar até $a_{i}$ dado que não falhou até $a_{i-1}$, considerando o vetor de covariáveis $\mathbf{x}_{l}$.

O teste tem como objetivo verificar qual função de ligação seria a mais adequada para um determinado conjunto de dados, uma vez que, esta família tem como casos particulares as transformações logit (modelo logístico) e complemento $\log$-log (modelo de Cox).

Assim, pela inversão de (10) tem-se o modelo ajustado a $p_{i}\left(\mathbf{x}_{l}\right)$, que é dado por:

$$
p_{i}\left(\mathbf{x}_{l}\right)= \begin{cases}1-\left(1+\lambda \exp \left(\eta_{l i}\right)\right)^{-1 / \lambda} & \text { se } \lambda \exp \left(\eta_{l i}\right)>-1 \\ 1 & \text { se } \lambda \exp \left(\eta_{l i}\right) \leq-1\end{cases}
$$

e tem como casos particulares as funções de ligações: logit,

$$
\eta_{l i}=\ln \left[p_{i}\left(\mathbf{x}_{l}\right) /\left(1-p_{i}\left(\mathbf{x}_{l}\right)\right)\right]
$$

quando $\lambda=1$ (modelo logístico) e complemento log-log,

$$
\eta_{l i}=\ln \left[-\ln \left(1-p_{i}\left(\mathbf{x}_{l}\right)\right)\right]
$$

quando $\lambda \rightarrow 0$ (modelo de Cox).

A estatística do teste escore para o modelo de Cox foi obtida para a hipótese nula $H_{0}: \lambda=0$, sendo dada por:

$$
S r=\frac{U_{\lambda}^{2}\left(0, \hat{\beta}, \hat{\gamma}^{*}\right)}{I_{\lambda \lambda}^{-1}\left(\hat{\theta}_{0}\right)}
$$

em que $I_{\lambda \lambda}\left(\theta_{0}\right)$ é a matriz de informação observada.

De forma análoga à estatística escore para o modelo de Cox, pode-se obter $S r_{1}$, para testar a hipótese $H_{0}: \lambda=1$ (modelo logístico), dada por:

$$
S r_{1}=\frac{U_{\lambda}^{2}\left(\hat{\theta}_{1}\right)}{I_{\lambda \lambda}\left(\hat{\theta}_{1}\right)-I_{\lambda \phi}\left(\hat{\theta}_{1}\right) I_{\phi \phi}^{-1}\left(\hat{\theta}_{1}\right) I_{\phi \lambda}\left(\hat{\theta}_{1}\right)},
$$

em que:

$$
I_{\lambda \phi}\left(\theta_{1}\right)=\left[\begin{array}{ll}
I_{\lambda \gamma^{*}}\left(\theta_{1}\right) & I_{\lambda \beta}\left(\theta_{1}\right)
\end{array}\right]
$$


e

$$
I_{\phi \phi}\left(\hat{\theta}_{1}\right)=\left[\begin{array}{cc}
I_{\gamma^{*} \gamma^{*}}\left(\theta_{1}\right) & I_{\gamma^{*} \beta}\left(\theta_{1}\right) \\
I_{\beta \gamma^{*}}\left(\theta_{1}\right) & I_{\beta \beta}\left(\theta_{1}\right)
\end{array}\right]
$$

em que, $I_{\lambda \lambda}\left(\theta_{1}\right), I_{\lambda \gamma^{*}}\left(\theta_{1}\right), I_{\lambda \beta}\left(\theta_{1}\right), I_{\gamma^{*} \gamma^{*}}\left(\theta_{1}\right), I_{\gamma^{*} \beta}\left(\theta_{1}\right)$ e $I_{\beta \beta}\left(\theta_{1}\right)$ são os limites das derivadas parciais de segunda ordem do logaritmo da função dada em (4).

As estatísticas $S r$ e $S r_{1}$ têm distribuição aproximadamente quiquadrado com 1 grau de liberdade.

Um procedimento para a escolha de modelos lineares não encaixados baseado no critério de Informação de Akaike (Akaike,1973) e no Critério Bayesiano de Informação (Schwartz, 1978) foi apresentado por Lindsey \& Jones (1998). Os autores fizeram comparações entre modelos lineares generalizados utilizando dados de contagens de células no sangue em diagnóstico médico. Para pequenas amostras os resultados obtidos pelos dois critérios são próximos. 


\section{METODOLOGIA}

\subsection{Modelos para dados com censura intervalar}

Considerando-se uma amostra de $n$ indivíduos cujos tempos de vida, $T_{l}, l=1, \ldots, n$, são agrupados em $k$ intervalos, $I_{i}=\left[a_{i-1}, a_{i}\right), i=1, \ldots, k$, com $0=a_{0}<a_{1}<\ldots<a_{k}=\infty$ e um vetor de covariáveis $\mathbf{x}_{\mathbf{l}}, l=1, \ldots, n$. Seja $D_{i}$ o conjunto dos indivíduos que falharam no intervalo $I_{i} ; R_{i}$, o conjunto dos indivíduos sob risco no início de $I_{i}$, e $\Delta_{l i}$, a variável indicadora de falha do l-ésimo indivíduo em $I_{i}$, que assume valor zero quando a $l$-ésima observação é censurada no $i$-ésimo intervalo, e um em caso contrário, para $i=1, \ldots, k, l=1, \ldots, n$. Assumindo-se que todas as censuras ocorrem no final do intervalo. A probabilidade do $l$-ésimo indivíduo falhar até $a_{i}$ dado que não falhou até $a_{i-1}$, considerando o vetor de covariáveis $\mathbf{x}_{l}$ é expressa por:

$$
p_{i}\left(\mathbf{x}_{l}\right)=P\left(T_{l} \leq a_{i} \mid T_{l} \geq a_{i-1}, \mathbf{x}_{l}\right) .
$$

Em termos da função de sobrevivência (11) pode ser escrita como:

$$
\begin{aligned}
p_{i}\left(\mathbf{x}_{l}\right) & =1-P\left(T_{l} \geq a_{i} \mid T_{l} \geq a_{i-1}, \mathbf{x}_{l}\right) \\
& =1-\frac{S\left(a_{i} \mid \mathbf{x}_{l}\right)}{S\left(a_{i-1} \mid \mathbf{x}_{l}\right)}
\end{aligned}
$$

em que $S\left(a_{i} \mid \mathbf{x}_{l}\right) / S\left(a_{i-1} \mid \mathbf{x}_{l}\right)$ é a probabilidade do l-ésimo indivíduo não falhar até $a_{i}$ dado que ele não falhou até $a_{i-1}$. 
Assim, a função de verossimilhança em termos da probabilidade condicional $p_{i}\left(\mathbf{x}_{l}\right)$ é dada por:

$$
\begin{aligned}
L & =\prod_{i=1}^{k}\left[\prod_{l \in D_{i}} p_{i}\left(\mathbf{x}_{l}\right) \prod_{l \in R_{i}-D_{i}}\left(1-p_{i}\left(\mathbf{x}_{l}\right)\right)\right] \\
& =\prod_{i=1}^{k} \prod_{l \in R_{i}}\left(p_{i}\left(\mathbf{x}_{l}\right)\right)^{\Delta_{l i}}\left(1-p_{i}\left(\mathbf{x}_{l}\right)\right)^{\left(1-\Delta_{l i}\right)}
\end{aligned}
$$

que corresponde à função de verossimilhança para variáveis com distribuição de Bernoulli, pois a variável $\Delta_{l i}$ é binária (isto é, ocorreu a falha, ou não, no intervalo $\left.I_{i}\right)$.

As probabilidades $p_{i}\left(\mathbf{x}_{l}\right)$ podem ser modeladas através dos modelos de riscos proporcionais de Cox ou logístico e as covariáveis associadas aos indivíduos podem ser fatores.

\subsubsection{Modelo de riscos proporcionais de Cox}

Como já visto em (8), a função de risco para $T$ dado o vetor de covariáveis $\mathbf{x}_{l}$ é, de acordo com o modelo de Cox, dada por:

$$
h\left(t \mid \mathbf{x}_{l}\right)=h_{0}(t) \exp \left(\boldsymbol{\beta}^{\prime} \mathbf{x}_{l}\right)
$$

e a função de sobrevivência dado o vetor de covariáveis $\mathbf{x}_{l}$ é:

$$
S\left(t \mid \mathbf{x}_{l}\right)=\exp \left(-\int_{0}^{t} h(u \mid \mathbf{x}) d u\right)=\left[S_{0}(t)\right]^{\exp \left(\boldsymbol{\beta}^{\prime} \mathbf{x}_{l}\right)}
$$

sendo $S_{0}(t)$ a função de sobrevivência de base.

Assim, a partir de (14), $p_{i}\left(\mathbf{x}_{l}\right)$ pode ser escrita como:

$$
p_{i}\left(\mathbf{x}_{l}\right)=1-\left[\frac{S_{0}\left(a_{i}\right) \mid \mathbf{x}_{l}}{S_{0}\left(a_{i-1} \mid \mathbf{x}_{l}\right)}\right]^{\exp \left(\boldsymbol{\beta}^{\prime} \mathbf{x}_{l}\right)}
$$


ou ainda,

$$
p_{i}\left(\mathbf{x}_{l}\right)=1-\gamma_{i}^{\exp \left(\boldsymbol{\beta}^{\prime} \mathbf{x}_{l}\right)}
$$

em que $\gamma_{i}=S_{0}\left(a_{i} \mid \mathbf{x}_{l}\right) / S_{0}\left(a_{i-1} \mid \mathbf{x}_{l}\right)$.

Substituindo (15) em (13), a função de verossimilhança fica da seguinte forma:

$$
L=\prod_{i=1}^{k} \prod_{l \in R_{i}}\left(1-\gamma_{i}^{\exp \left(\boldsymbol{\beta}^{\prime} \mathbf{x}_{l}\right.}\right)^{\Delta_{l i}}\left(\gamma_{i}^{\exp \left(\boldsymbol{\beta}^{\prime} \mathbf{x}_{l}\right.}\right)^{1-\Delta_{l i}}
$$

O logaritmo da função de verossimilhança é então dado por:

$$
l(\boldsymbol{\beta}, \boldsymbol{\gamma})=\ln L(\boldsymbol{\beta}, \boldsymbol{\gamma})=\sum_{i=1}^{k} \sum_{l \in R_{i}}\left(\Delta_{l i} \ln \left(1-\gamma_{i}^{\exp \left(\boldsymbol{\beta}^{\prime} \mathbf{x}_{l}\right)}\right)+\left(1-\Delta_{l i}\right) \ln \left(\gamma_{i}^{\exp \left(\boldsymbol{\beta}^{\prime}{ }_{\left.\mathbf{x}_{l}\right)}\right)}\right)\right)
$$

Como os $p_{i}(\mathbf{x})$ são restritos ao intervalo [0,1], é conveniente se utilizar a reparametrização $\gamma_{i}^{*}=\ln \left(-\ln \left(\gamma_{i}\right)\right)$ sugerida por Prentice \& Gloeckler (1978), sendo os $\gamma_{i}^{*}=\gamma_{1}^{*}, \ldots, \gamma_{k}^{*}$ irrestritos melhorando a convergência no processo iterativo para a estimação desses parâmetros. Assim, o logaritmo da função de verossimilhança fica:

$$
l(\boldsymbol{\beta}, \boldsymbol{\gamma})=\sum_{i=1}^{k} \sum_{l \in R_{i}}\left[-\left(1-\Delta_{l i}\right) \exp \left(\gamma_{i}^{*}+\boldsymbol{\beta}^{\prime} \mathbf{x}_{l}\right)+\Delta_{l i} \ln \left(1-\exp \left(-\exp \left(\gamma_{i}^{*}+\boldsymbol{\beta}^{\prime} \mathbf{x}_{l}\right)\right)\right)\right]
$$

em que $\boldsymbol{\gamma}=\left(\gamma_{1}, \ldots, \gamma_{k}\right)^{\prime}$.

As equações de verossimilhança são dadas por:

$$
\begin{aligned}
& \frac{\partial l(\boldsymbol{\beta}, \boldsymbol{\gamma})}{\partial \beta_{j}}=\sum_{i=1}^{k} \sum_{l \in R_{i}}\left[\frac{\Delta_{l i} x_{l j} \exp \left(\gamma_{i}^{*}+\boldsymbol{\beta}^{\prime} \mathbf{x}_{l}\right)}{\exp \left(\exp \left(\gamma_{i}^{*}+\boldsymbol{\beta}^{\prime} \mathbf{x}_{l}\right)\right)-1}-\left(1-\Delta_{l i}\right) x_{l j} \exp \left(\gamma_{i}^{*}+\boldsymbol{\beta}^{\prime} \mathbf{x}_{l}\right)\right] \\
& \frac{\partial l(\boldsymbol{\beta}, \boldsymbol{\gamma})}{\partial \gamma_{i}^{*}}=\sum_{l \in R_{i}}\left[\frac{\Delta_{l i} \exp \left(\gamma_{i}^{*}+\boldsymbol{\beta}^{\prime} \mathbf{x}_{l}\right)}{\exp \left(\exp \left(\gamma_{i}^{*}+\boldsymbol{\beta}^{\prime} \mathbf{x}_{l}\right)\right)-1}-\left(1-\Delta_{l i}\right) \exp \left(\gamma_{i}^{*}+\boldsymbol{\beta}^{\prime} \mathbf{x}_{l}\right)\right]
\end{aligned}
$$

com $j=1, \ldots, p$ e $i=1, \ldots, k$, que quando igualadas a zero podem ser resolvidas por um método iterativo. 


\subsubsection{Modelo logístico}

Adotando-se o modelo logístico, tem-se que:

$$
p_{i}\left(\mathbf{x}_{l}\right)=1-\left(1+\gamma_{i} \exp \left(\boldsymbol{\beta}^{\prime} \mathbf{x}_{l}\right)\right)^{-1},
$$

em que $\gamma_{i}=p_{i}(0) /\left(1-p_{i}(0)\right), i=1, \ldots, k$.

Assim, escrevendo-se a função de verossimilhança (13) considerando-se (16) tem-se:

$$
L(\boldsymbol{\beta}, \boldsymbol{\gamma})=\prod_{i=1}^{k} \prod_{l \in R_{i}}\left(\frac{\gamma_{i} \exp \left(\boldsymbol{\beta}^{\prime} \mathbf{x}_{l}\right)}{1+\gamma_{i} \exp \left(\boldsymbol{\beta}^{\prime} \mathbf{x}_{l}\right)}\right)^{\Delta_{l i}}\left(\frac{1}{1+\gamma_{i} \exp \left(\boldsymbol{\beta}^{\prime} \overline{\mathbf{x}}_{l}\right)}\right)^{\mathbf{1}-\Delta_{l i}} .
$$

Usando-se a reparametrização $\gamma_{i}^{*}=\ln \left(\gamma_{i}\right)$, sugerida por Lawless (1982) para melhorar a convergência e aproximar a distribuição assintótica dos estimadores de máxima verossimilhança para a distribuição normal, o logaritmo da função de verossimilhança fica:

$$
l(\boldsymbol{\beta}, \boldsymbol{\gamma})=\ln (L(\boldsymbol{\beta}, \boldsymbol{\gamma}))=\sum_{i=1}^{k} \sum_{l \in R_{i}} \Delta_{l i}\left(\gamma_{i}^{*}+\boldsymbol{\beta}^{\prime} \mathbf{x}_{l}\right)-\ln \left(1+\exp \left(\gamma_{i}^{*}+\boldsymbol{\beta}^{\prime} \mathbf{x}_{l}\right)\right)
$$

e as equações de verossimilhança são dadas por:

$$
\begin{aligned}
& \frac{\partial l(\boldsymbol{\beta}, \boldsymbol{\gamma})}{\partial \boldsymbol{\beta}_{\boldsymbol{j}}}=\sum_{i=1}^{k} \sum_{l \in R_{i}} x_{l j} \Delta_{l i}-\left[\frac{x_{l j} \exp \left(\gamma_{i}^{*}+\boldsymbol{\beta}^{\prime} \mathbf{x}_{l}\right)}{1+\exp \left(\alpha_{i}+\boldsymbol{\beta}^{\prime} \mathbf{x}_{l}\right)}\right], \\
& \frac{\partial l(\boldsymbol{\beta}, \boldsymbol{\gamma})}{\partial \gamma_{i}}=\sum_{i=1}^{k} \sum_{l \in R_{i}} \Delta_{l i}-\left[\frac{\exp \left(\gamma_{i}^{*}+\boldsymbol{\beta}^{\prime} \mathbf{x}_{l}\right)}{1+\exp \left(\gamma_{i}^{*}+\boldsymbol{\beta}^{\prime} \mathbf{x}_{l}\right)}\right],
\end{aligned}
$$

em que $j=1, \ldots, p$ e $i=1, \ldots, k$, que quando igualadas a zero podem ser resolvidas usando um processo iterativo. 


\subsection{Utilizaçāo dos modelos lineares generalizados para o ajuste dos modelos logístico e de Cox}

Whitehead (1989) ajustou o modelo de riscos proporcionais de Cox para dados com censura intervalar utilizando a transformação complemento log-log a $1-p_{i}\left(\mathbf{x}_{l}\right)$, dado por (14), e considerando a variável indicadora de falha, $\Delta_{l i}$, como a variável resposta.

Assim, aplicando-se a transformação complemento $\log$-log em (15), temse:

$$
\ln \left(-\ln \left(1-p_{i}\left(\mathbf{x}_{l}\right)\right)\right)=\boldsymbol{\beta}^{\prime} \mathbf{x}_{l}+\ln \left(-\ln \left(\gamma_{i}\right)\right) \quad i=1, \ldots, k \quad l=1, \ldots, n
$$

ou ainda,

$$
\ln \left(-\ln \left(1-p_{i}\left(\mathbf{x}_{l}\right)\right)\right)=\boldsymbol{\beta}^{\prime} \mathbf{x}_{l}+\gamma_{i}^{*} \quad i=1, \ldots, k \quad l=1, \ldots, n
$$

em que $\gamma_{i}^{*}=\ln \left(-\ln \left(\gamma_{i}\right)\right)$ são parâmetros incorporados ao modelo para ajustar os termos correspondentes aos $k$-níveis do fator associado ao intervalo de tempo.

No caso do ajuste do modelo logístico, a transformação utilizada é a logit e a variável resposta também é a variável indicadora de censura, $\Delta_{l i}$.

Assim, a transformação logit aplicada em (16), resulta em:

$$
\ln \left(\frac{p_{i}\left(\mathbf{x}_{l}\right)}{1-p_{i}\left(\mathbf{x}_{l}\right)}\right)=\ln \left(\gamma_{i}\right)+\boldsymbol{\beta}^{\prime} \mathbf{x}_{l}=\gamma_{i}^{*}+\boldsymbol{\beta}^{\prime} \mathbf{x}_{l}=\eta_{l i}
$$

em que $\gamma_{i}^{*}=\ln \left(\gamma_{i}\right)$ corresponde ao efeito de intervalo de tempo. 


\subsection{Planos de reamostragem}

Em modelos de regressão ou em modelos seguindo algum tipo de delineamento experimental, uma maneira prática de se fazer replicações bootstrap é reamostrar os resíduos, de acordo com Davidson \& Hinkey (1997).

No presente trabalho, inicialmente, será feito o ajuste dos modelos de Cox e logístico para dados com censura intervalar com o auxílio dos modelos lineares generalizados. A fim de verificar a possiblidade de selecionar um dos modelos citados, o procedimento a ser seguido, considerando $M_{c}$ e $M_{l}$ como os modelos de riscos proporcionais de Cox e o logístico, respectivamente, será:

1. Ajustam-se os modelos $M_{c}$ e $M_{l}$ com os dados da amostra original e calcula-se a diferença de deviances entre os dois modelos, dada por:

$$
d_{o b s}=D_{c}-D_{l}
$$

em que $D_{c}$ e $D_{l}$ são as deviances referentes aos ajustes dos modelos $M_{c}$ e $M_{l}$, respectivamente. Com os parâmetros estimados através do ajuste inicial de $M_{c}$, obtêm-se os resíduos e reamostram-se esses resíduos um número $B$ de vezes, obtendo-se $B$ resíduos bootstrap. Com esses $B$ resíduos bootstrap, geram-se as novas observações bootstrap como descritas em (3.3.1). Novamente, faz-se o ajuste dos modelos $M_{c}$ e $M_{l}$ aos dados das amostras bootstrap, calculando-se as diferenças de deviances, dada agora por:

$$
d_{c b}=D_{c}-D_{l}
$$

para $b=1, \ldots, B$

2. De modo análogo, com os parâmetros estimados através do ajuste inicial de $M_{l}$, obtêm-se os resíduos e reamostram-se esses resíduos um número $B$ de vezes, obtendo-se $B$ resíduos bootstrap. Com esses $B$ resíduos, obtêm-se as 
novas observações bootstrap de forma análoga ao item anterior. A seguir, fazse o ajuste para $M_{c}$ e $M_{l}$ com os novos dados obtidos da amostra bootstrap, calculando-se as diferenças de deviances, agora dada por:

$$
d_{l b}=D_{c}-D_{l}
$$

$\operatorname{para} b=1, \ldots, B$

3. O valor de $d_{o b s}$ será, então, comparado aos valores obtidos das diferenças de deviances $\left\{d_{c b}\right\}$ e $\left\{d_{l b}\right\}$ obtidos com a simulação bootstrap. Com o objetivo de verificar a evidência de um modelo em relação a outro, serão construídos histogramas para verificar a distribuição de $\left\{d_{c b}\right\}$ e $\left\{d_{l b}\right\}$ e serão propostos os respectivos níveis de significância empíricos, dados por:

- nível de significância $=\frac{1}{B} \sum_{b=1}^{B} I\left(d_{c b}>d_{o b s}\right)$ para o modelo de Cox

- nível de significância $=\frac{1}{B} \sum_{b=1}^{B} I\left(d_{l b}>d_{o b s}\right)$ para o modelo logístico

em que $I($.$) é a função indicadora do número de vezes que as diferenças de$ deviances de ambos os modelos supera a $d_{o b s}$.

Caso a diferença de deviances $d_{o b s}$ seja negativa, os níveis de significância serão calculados apenas trocando o sinal de $>$ (maior) pelo sinal de $<$ (menor), ou seja, nesse caso deverá ter uma maior concentração de valores negativos na distribuição empírica da diferença de deviances para que o modelo considerado como verdadeiro (hipótese nula) não seja rejeitado.

A simulação bootstrap será realizada com a reamostragem dos seguintes resíduos:

\section{- Resíduo simples}

$$
r_{i}=y_{i}-\hat{\mu}_{i}, \quad i=1,2, \ldots, n
$$

em que $\hat{\mu}_{i}$ são os valores ajustados; 


\section{- Resíduo de Pearson}

$$
r_{P i}=\frac{y_{i}-\hat{\mu}_{i}}{\left[V\left(\mu_{i}\right)\right]^{1 / 2}}, \quad i=1,2, \ldots, n
$$

em que $V\left(\mu_{i}\right)$ é a função de variância;

\section{- Resíduo de Pearson padronizado}

$$
r_{P P i}=\frac{y_{i}-\hat{\mu}_{i}}{\left[c_{i} \hat{k} V\left(\hat{\mu}_{i}\right)\left(1-h_{i}\right)\right]^{1 / 2}}, \quad i=1,2, \ldots, n .
$$

em que os valores $h_{i}$ são os elementos da diagonal da matriz $H$ dada por $H=W^{(1 / 2)} X\left(X^{\prime} W X\right)^{-1} X^{\prime} W^{1 / 2}, c_{i}$ são pesos conhecidos e $k$ é o parâmetro de dispersão que pode ser desconhecido. Para dados binomiais com probabilidade $\pi\left(x_{i}\right)$ e denominador $m_{i}, c_{i}=1 / m_{i}$ e $k$ é constante e igual a 1.

Os planos de reamostragem serão, então, elaborados com base nesses resíduos e, para medir a qualidade da discrepância entre os dois modelos, será analisada a diferença de deviances, observando-se em direção a qual dos modelos ajustados seu valor está situado. Programas em S-Plus, V. 3.3, serão elaborados para a simulação bootstrap.

\subsubsection{Obtenção das amostras bootstrap}

A obtenção das amostras bootstrap está baseada em Davison \& Hinkley (1997), considerando cada tipo de resíduo e está definida como segue:

- Resíduo simples

$$
y_{b o o t}^{*}=\hat{y}+\varepsilon_{i}^{*}
$$


em que $\hat{\mu}$ é o valor ajustado e $\varepsilon_{i}^{*}$ é uma amostra bootstrap dos resíduos simples sob os modelos a serem considerados $\left(M_{c}\right.$ ou $\left.M_{l}\right)$.

\section{- Resíduo de Pearson}

$$
y_{b o o t P i}^{*}=\hat{\mu}+V\left(\hat{\mu}_{i}\right) \varepsilon_{P i}^{*}
$$

em que $\varepsilon_{P i}^{*}$ é uma amostra bootstrap dos resíduos de Pearson sob os modelos a serem considerados $\left(M_{c}\right.$ ou $\left.M_{l}\right)$.

\section{- Resíduo de Pearson Padronizado}

$$
\left.y_{b o o t P P i}^{*}=\hat{\mu}+c_{i} \hat{k} V\left(\hat{\mu}_{i}\right)\left(1-h_{i}\right)\right]^{1 / 2} \varepsilon_{P P i}^{*}
$$

em que $\varepsilon_{P P i}^{*}$ é uma amostra bootstrap dos resíduos de Pearson padronizados sob os modelos a serem considerados $\left(M_{c}\right.$ ou $\left.M_{l}\right)$.

\subsection{Aplicações}

Como aplicação da metodologia proposta neste trabalho, serão utilizados dois conjuntos de dados resultantes de dois experimentos agronômicos, sendo o primeiro da área de Fitopatologia e o segundo da Entomologia e, pelo fato dos dois conjuntos de dados apresentarem alta proporção de empates, serão analisados pelos modelos de tempo de vida discretos de Cox e logístico.

\subsubsection{Aplicaçāo em Fitopatologia}

O experimento foi realizado com um cultivar de linho, susceptível ao patógeno Fusarium oxysporum, plantado sobre quatro substratos: M: solo natural 
(controle), MI:M + ilita, MK:M + caolinita e MM:M + montmorilonita. Este conjunto de dados foi estudado e apresentado em Chalita (1997). Neste experimento à suscetibilidade dos cultivares à murcha causada pelo patógeno, foi observada através do tempo até a planta murchar. As avaliações foram feitas aos 21, 24, 28, 31, 35, 38, 42,45 e 49 dias gerando uma proporção de empates de $27 \%$. Portanto, o tempo pode ser considerado como uma variável discreta e os modelos de Cox e logístico podem ser ajustados.

\subsubsection{Aplicação em Entomologia}

O experimento foi realizado pelas pesquisadoras Elisabeth de Nardo e Maria Aico Watanabe no laboratório de Entomologia da EMBRAPA/Meio ambiente - Jaguariúna - SP com o objetivo de avaliar o efeito de uma formulação da Anticarsia gemmatalis Nuclear Polyhedrosis Virus (AgNPV) sobre o predador Podysus nigrispinus Dallas. A Anticarsia gemmatalis é uma praga que ataca a soja e o seu principal predador é o inseto Podysus nigrispinus, que realiza um controle natural desta praga. Alternativamente, agentes entomopatogênicos ou patógenos (virus, bactérias, fungos

e nematóides) estão sendo bastante utilizados no controle biológico de pestes e são considerados menos agressivos para o ambiente do que pesticidas químicos, embora tenham a desvantagem de infectarem outros organismos que são úteis ao ambiente. $\mathrm{O}$ risco associado com esses agentes de biocontrole tem aumentado consideravelmente e, portanto, estão sendo motivo de estudo em todo o mundo.

Neste experimento foram utilizados dois tratamentos, um com a larva infectada com AgNPV (grupo tratado) e o outro com a larva sadia (grupo controle), o interesse é avaliar se o virus atinge o predador influenciando no seu tempo de vida. Outro fator considerado foi o sexo dos insetos Podysus nigrispinus. A variável observada foi o tempo em que o predador atingia a fase adulta e os tempos avaliados foram $24,25,26,27$ e 28 dias. Devido aos poucos intervalos e aos empates, o tempo 
pode ser considerado como uma variável discreta e novamente os modelos de Cox e logístico podem ser ajustados.

Em ambos os casos serão ajustados os modelos de Cox e logístico, realizar-se-á uma simulação bootstrap, além de uma discussão sobre a escolha do modelo e da metodologia empregada. 


\section{RESULTADOS E DISCUSSÃO}

\subsection{Aplicaçāo com cultivar de linho}

A fim de avaliar a sobrevivência do cultivar de linho nos quatro substratos, foi realizada uma análise descritiva dos dados através do teste Log-rank e construiu-se as curvas de sobrevivência para cada susbtrato considerando o estimador tabela de vida. O teste log-rank forneceu um $p$-valor $=0,0002$, evidenciando assim, diferença significativa entre os tipos de substratos. Pela análise da Figura 1, podese verificar que o substrato $\mathrm{M}$ (solo natural) é o que apresenta menor resistência à murcha causada pelo patógeno.

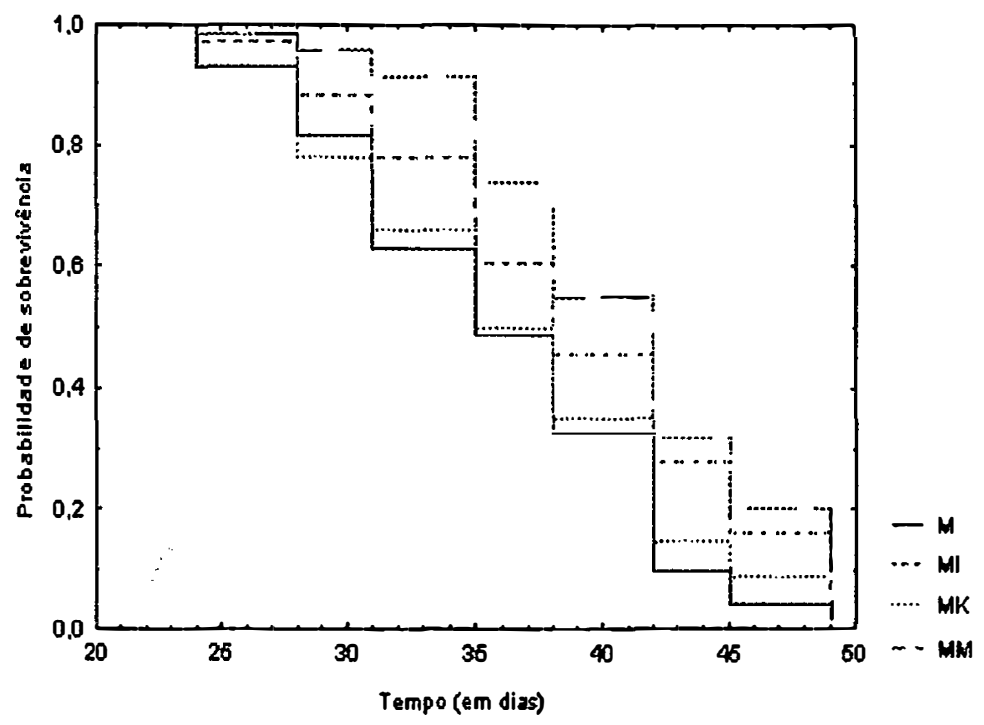

Figura 1 - Curvas de sobrevivência estimadas pela tabela de vida versus tempo de vida em dias para cada substrato. 
A seguir, foram ajustados a esses dados os modelos de Cox e logístico. A Tabela 4 mostra a análise de deviances obtida para o ajuste dos dois modelos.

Tabela 4. Análise de deviances do experimento com o cultivar de linho.

\begin{tabular}{c|c|cc}
\hline Causas de Variação & GL & \multicolumn{2}{|c}{ Deviances } \\
\cline { 3 - 4 } & & Modelo de Cox & Modelo Logístico \\
\hline Nula & 34 & 225,894 & 225,894 \\
Intervalo & 8 & $188,427^{* *}$ & $188,427^{* *}$ \\
Solo & 3 & $17,378^{* *}$ & $18,253^{* *}$ \\
Residual & 23 & 20,089 & 19,214 \\
\hline
\end{tabular}

** - significativo ao nível de $1 \%$

Pela análise da Tabela 4, pode-se comprovar que tanto o efeito de intervalo quanto o de solo foram significativos para os dois modelos considerados. Assim, para o modelo de Cox tem-se:

$$
\ln \left[-\ln \left(1-p_{i}\left(\mathbf{x}_{l}\right)\right)\right]=\gamma_{i}^{*}+\alpha_{j},
$$

e, portanto;

$$
p_{i}\left(\mathbf{x}_{l}\right)=1-\left[\exp \left(-\exp \left(\gamma_{i}^{*}\right)\right)\right]^{\exp \left(\alpha_{j}\right)},
$$

e, para o modelo logístico, tem-se:

$$
\ln \left[\frac{p_{i}\left(\mathbf{x}_{l}\right)}{1-p_{i}\left(\mathbf{x}_{l}\right)}\right]=\gamma_{i}^{*}+\alpha_{j}
$$

e, assim

$$
p_{i}\left(\mathbf{x}_{l}\right)=1-\left[1+\exp \left(\gamma_{i}^{*}+\alpha_{j}\right)\right]^{-1}
$$

em que: 
- $p_{i}\left(\mathbf{x}_{l}\right)$ é a probabilidade da $l$-ésima planta murchar no $i$-ésimo intervalo, dado que não murchou até o intervalo anterior, considerando cada tipo de solo.

- $\gamma_{i}^{*}$ é o efeito do $i$-ésimo intervalo, $i=1, \ldots, 10$;

- $\alpha_{j}$ é o efeito do $j$-ésimo substrato, $j=1, \ldots, 4$.

A Tabela 5 apresenta as estimativas dos parâmetros com seus respectivos erros padrões, segundo os dois modelos considerados.

Tabela 5. Estimativas dos parâmetros obtidas através dos ajustes dos modelo de Cox e logístico para os dados do experimento com cultivar de linho.

\begin{tabular}{c|cc|cc}
\hline \multirow{2}{*}{ Parâmetros } & \multicolumn{2}{|c|}{ Modelo de Cox } & \multicolumn{2}{c}{ Modelo Logístico } \\
\cline { 2 - 5 } & estimativas & erro padrão & estimativa & erro padrão \\
\hline$\gamma_{1}^{*}$ & $-3,1356$ & 0,3455 & $-3,0650$ & 0,3567 \\
$\gamma_{2}^{*}$ & $-1,8503$ & 0,3799 & $-1,7335$ & 0,3902 \\
$\gamma_{3}^{*}$ & $-1,6775$ & 0,3784 & $-1,5489$ & 0,3898 \\
$\gamma_{4}^{*}$ & $-1,1102$ & 0,3655 & $-0,9108$ & 0,3787 \\
$\gamma_{5}^{*}$ & $-0,8603$ & 0,3663 & $-0,6244$ & 0,3825 \\
$\gamma_{6}^{*}$ & $-0,1089$ & 0,3594 & 0,2950 & 0,3851 \\
$\gamma_{7}^{*}$ & $-0,4282$ & 0,3931 & $-0,1052$ & 0,4265 \\
$\gamma_{8}^{*}$ & 0,2280 & 0,3942 & 0,7773 & 0,4577 \\
$\gamma_{9}^{*}$ & 0,2118 & 0,4831 & 0,7513 & 0,6002 \\
$\alpha_{2}^{*}$ & $-0,5342$ & 0,1748 & $-0,6327$ & 0,2092 \\
$\alpha_{3}^{*}$ & $-0,1758$ & 0,1735 & $-0,2075$ & 0,2088 \\
$\alpha_{4}^{*}$ & $-0,6375$ & 0,1734 & $-0,7845$ & 0,2080 \\
\hline
\end{tabular}


A razão de risco é obtida pelo cálculo da $\exp \left(\alpha_{j}\right), j=1, \ldots, 4 \mathrm{e}$ encontra-se na Tabela 6 juntamente com o $p$-valor correspondente para cada modelo considerando os substratos M, MI e MM. Na comparação entre M e MI, tem-se que o risco de uma planta no substrato MI murchar é 0,9311 vezes o das plantas do substrato $\mathrm{M}$ considerando o modelo de Cox. Como o valor da razão de risco é inferior a 1 , é conveniente calcular o inverso deste valor. Assim, o valor do risco de uma planta do substrato M murchar é 1,88 vezes o das plantas do substrato MI. Já para o modelo logístico, o risco obtido foi de 1,71 , bastante próximo ao obtido pelo ajuste do modelo de Cox. O risco para os substratos M e MM foi de 2,19 (modelo de Cox) e 1,89 (modelo logístico), e a interpretação desses resultados é análoga aos anteriores. Com relação aos substratos $\mathrm{M}$ e MK, não foi constatada diferença significativa entre eles, uma vez que foi encontrado um $p$-valor de 0,3204 e 0,3109 para os modelos de Cox e logístico, respectivamente.

Tabela 6. Razão de risco e $p$-valor segundo o modelo adotado - Experimento com o cultivar de linho.

\begin{tabular}{c|cc|cc}
\hline \multirow{2}{*}{ Parâmetros } & \multicolumn{2}{|c|}{ Razão de risco } & \multicolumn{2}{c}{$p$-valor } \\
\cline { 2 - 5 } & Modelo de Cox & Modelo Logístico & Modelo de Cox & Modelo Logístico \\
\hline M/MI & 1,88 & 1,71 & 0,0025 & 0,0022 \\
M/MM & 2,19 & 1,89 & 0,0002 & 0,0002 \\
\hline
\end{tabular}

O critério de informação de Akaike (AIC) foi utilizado para comparar os modelos de Cox e logístico e os valores encontrados foram, respectivamente, 159,2 e 160,1, ou seja, os valores obtidos foram muito próximos, indicando que ambos os ajustes podem ser considerados razoáveis, não evidenciando um melhor ajuste de um modelo em relação a outro.

As curvas de sobrevivência estimadas para cada modelo considerado são mostradas nas Figuras 2 e 3. Novamente, pode-se notar que os gráficos são bastante similares. 


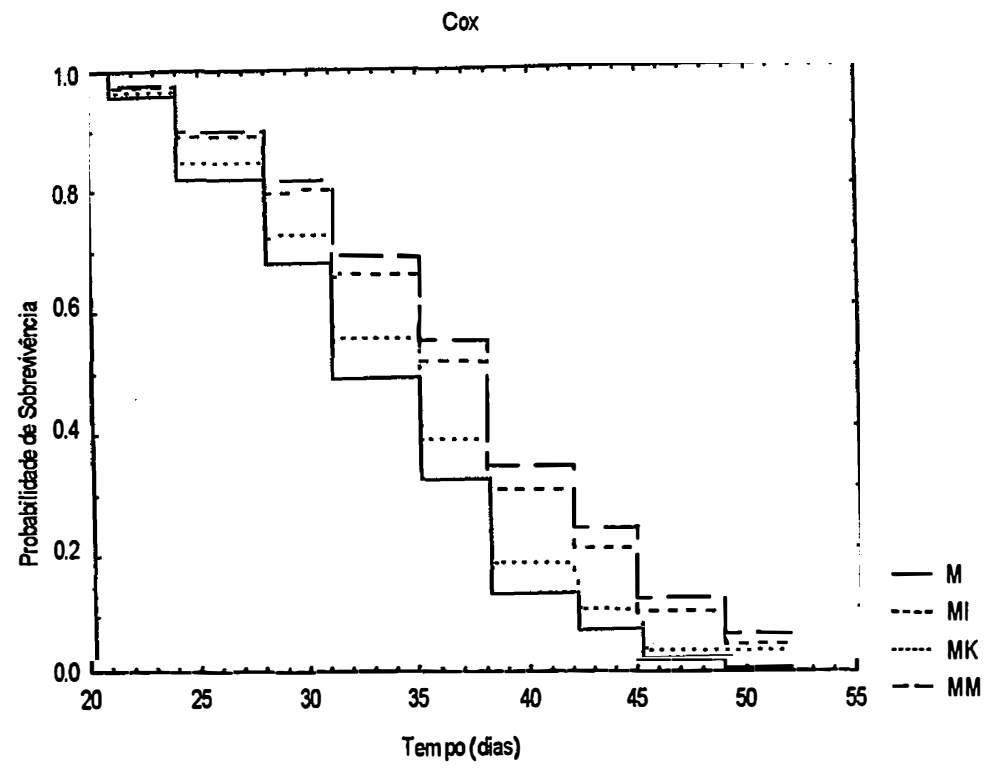

Figura 2 - Curva de sobrevivência segundo o tipo de solo ajustada para o modelo de Cox.

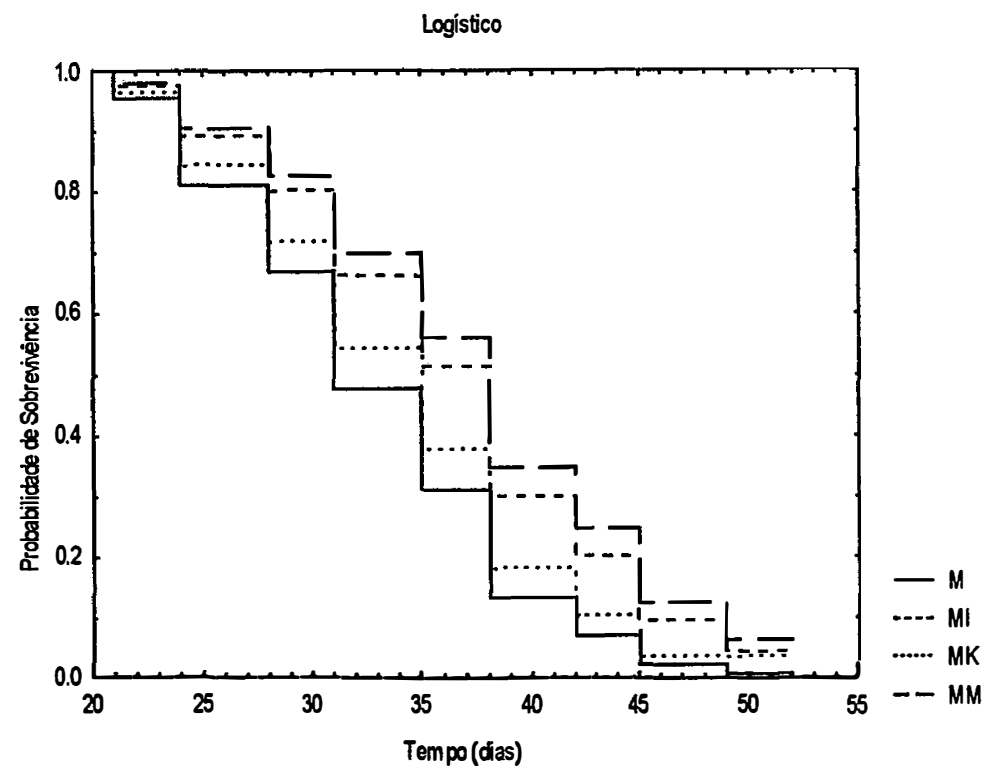

Figura 3 - Curva de sobrevivência segundo o tipo de solo ajustada para o modelo logístico. 
Desse modo, analisando os ajustes dos modelos de Cox e logístico através das deviances, das estimativas dos parâmetros e respectivos erros padrões dados na Tabela 5 , das razões de risco (Tabela 6), das curvas de sobrevivência estimadas e apresentadas nas Figuras 2 e 3 e pelo Critério de Informação de Akaike, praticamente não se pode dizer que o modelo logístico forneceu um melhor ajuste em relação ao modelo de Cox, uma vez que todos os resultados obtidos foram muito similares. Neste caso, qualquer um dos dois modelos poderia ser adotado para evidenciar a significância dos fatores considerados (intervalo e solo).

Apesar disso, é sempre interessante eleger um dos modelos como o que melhor se adequa aos dados e, em termos da deviance residual, o modelo logístico forneceu o menor valor, indicando um melhor ajuste.

Assim, como uma outra forma de evidenciar este fato, foi aplicada a metodologia proposta, calculando-se a diferença de deviances entre os modelos, $D_{o b s}=D_{c}-D_{l}=0,87$, que é um valor positivo e baixo. Desse modo, supondo-se que o modelo logístico é o verdadeiro, fez-se o ajuste para os dois modelos considerados e foram extraídos três tipos de resíduos: simples, de Pearson e de Pearson padronizados, cujas fórmulas foram apresentadas na seção anterior. $\mathrm{O}$ mesmo foi feito considerando o modelo de Cox como verdadeiro.

De posse desses resíduos, foram feitas 1000 replicações bootstrap recompondo as observações, agora chamadas de observações bootstrap, e novamente os dois modelos foram ajustados para cada caso e os níveis de significância foram calculados. Como o valor da $D_{o b s}$ foi positivo, para que o modelo suposto seja verdadeiro é de se esperar que o número de vezes que as deviances calculadas utilizando as observações bootstrap supere a deviance observada seja grande, evidenciando que a deviance do modelo suposto verdadeiro seja cada vez menor em relação a do outro modelo. Os valores dos níveis de significância para cada modelo são mostrados na Tabela 7 . 
Tabela 7. Níveis de significância obtidos através de 1000 replicações bootstrap segundo o tipo de resíduo e os modelos de Cox e logístico para os dados do experimento com o cultivar de linho.

\begin{tabular}{c|c|c}
\hline Tipos de resíduos & \multicolumn{2}{|c}{ Modelos } \\
\cline { 2 - 3 } & Modelo de Cox & Modelo Logístico \\
\hline Simples & 0,245 & 0,281 \\
Pearson & 0,195 & 0,328 \\
Pearson padronizado & 0,186 & 0,313 \\
\hline
\end{tabular}

Analisando a Tabela 7, nota-se que, para os três resíduos considerados , o modelo logístico sempre apresenta um nível de significância maior, evidenciando o resíduo de Pearson dentre os demais, embora a diferença entre este e o resíduo de Pearson padronizado seja pequena, o que mostra que a ponderação pela leverage praticamente não alterou os resultados. As Figuras 4, 5 e 6, mostram a distribuição empírica da $d_{o b s}$ após 1000 replicações bootstrap, considerando os resíduos simples, de Pearson e Pearson padronizados, para os modelos de Cox e logístico, respectivamente. Em todas as três figuras nota-se que a área acima da $d_{o b s}$ é maior para o modelo logístico.

Desse modo, através desta análise, tem-se novamente a indicação de que o modelo logístico é o mais adequado para ajustar esses dados. 
Modelo de Cox

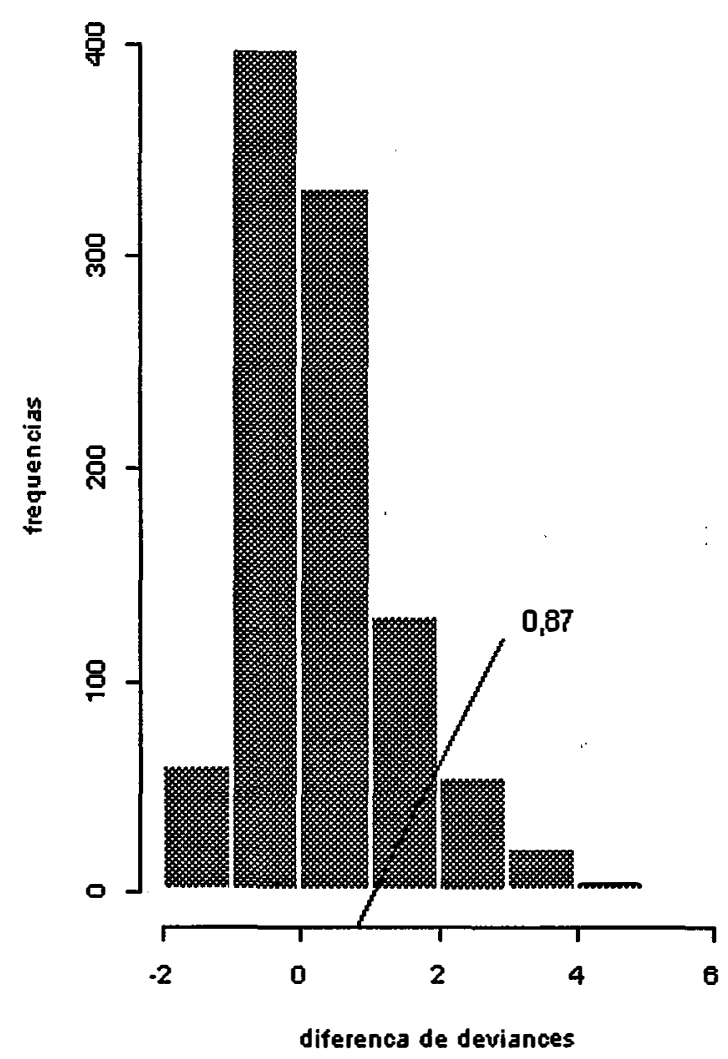

Modelo Logistico

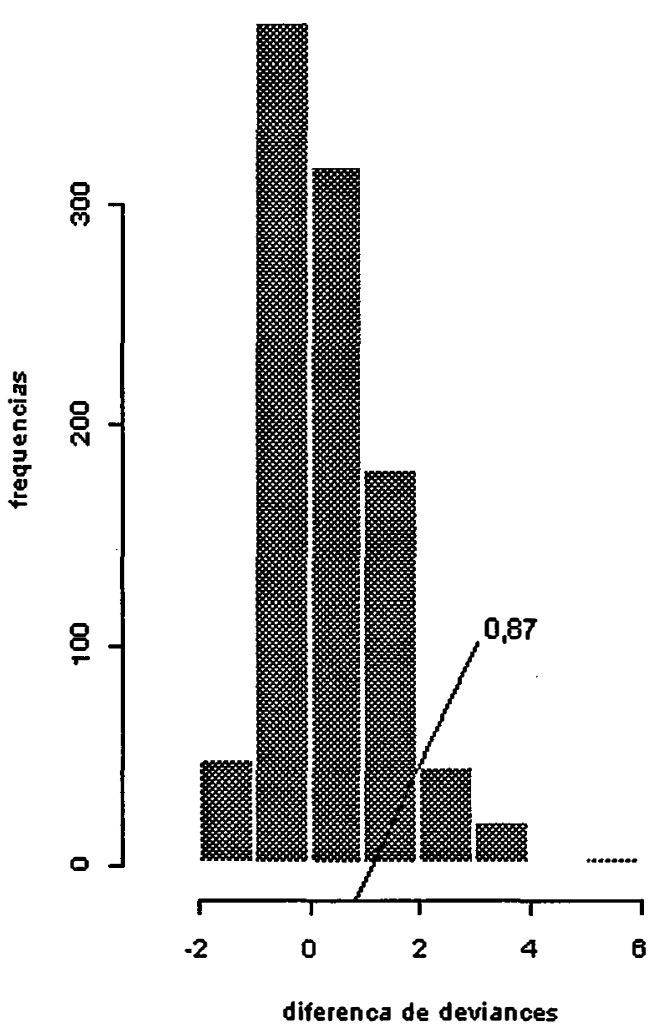

Figura 4 - Histograma da distribuição da diferença de deviances obtidas através de 1000 replicações bootstrap considerando os resíduos simples no ajuste dos modelos de Cox e logístico para os dados do experimento com cultivar de linho. 
Modelo de Cox

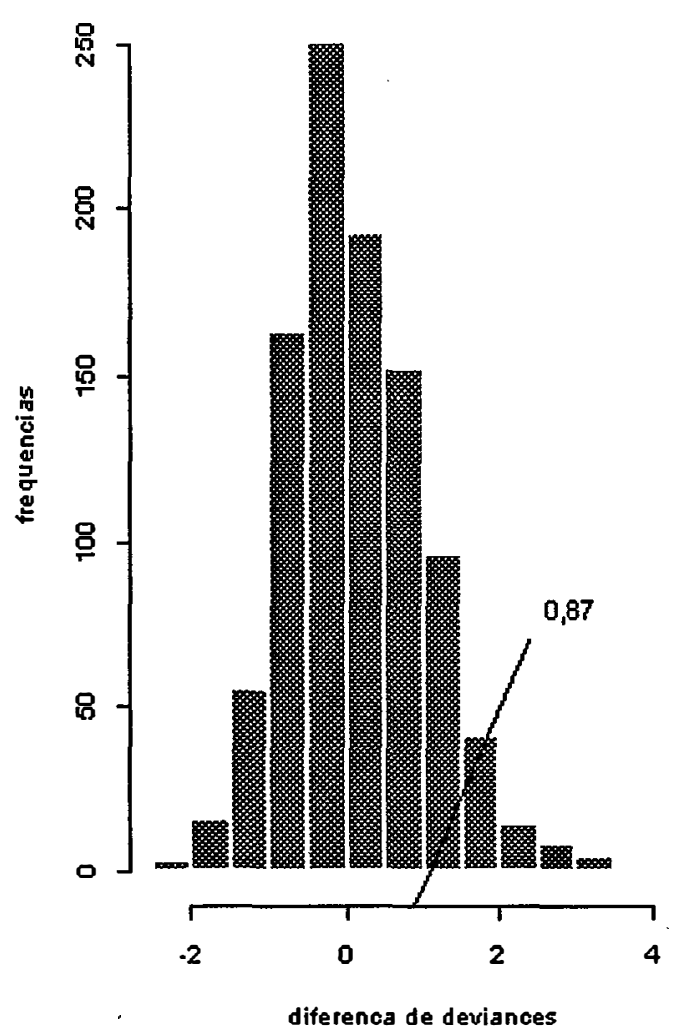

Modelo Logistico

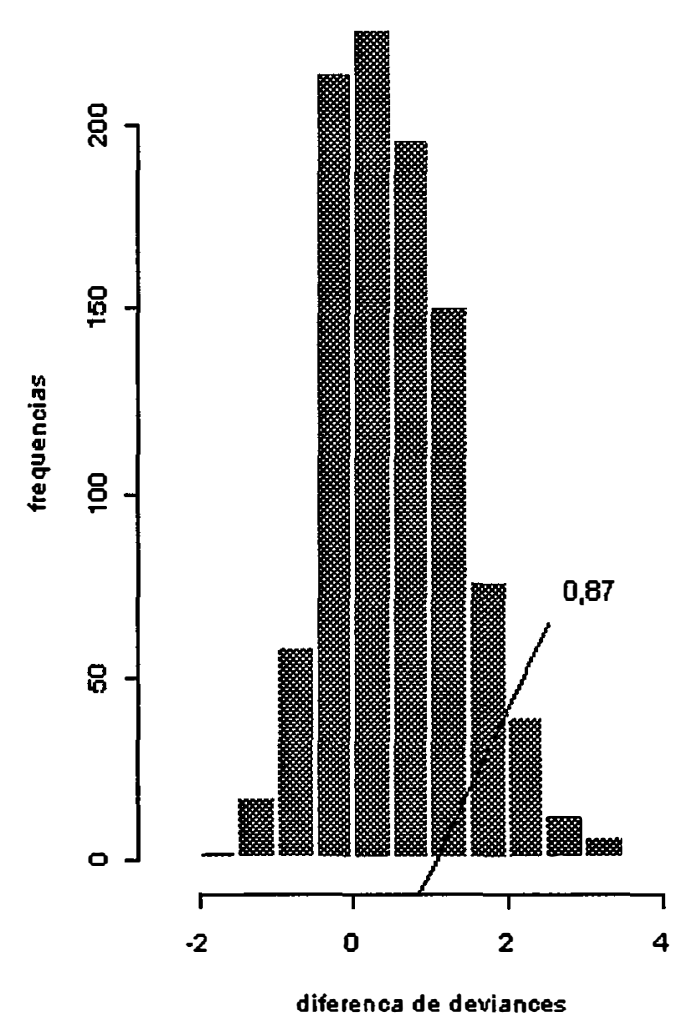

Figura 5 - Histograma da distribuição da diferença de deviances obtidas através de 1000 replicações bootstrap considerando os resíduos de Pearson no ajuste dos modelos de Cox e logístico para os dados do experimento com cultivar de linho. 
Modelo de Cox

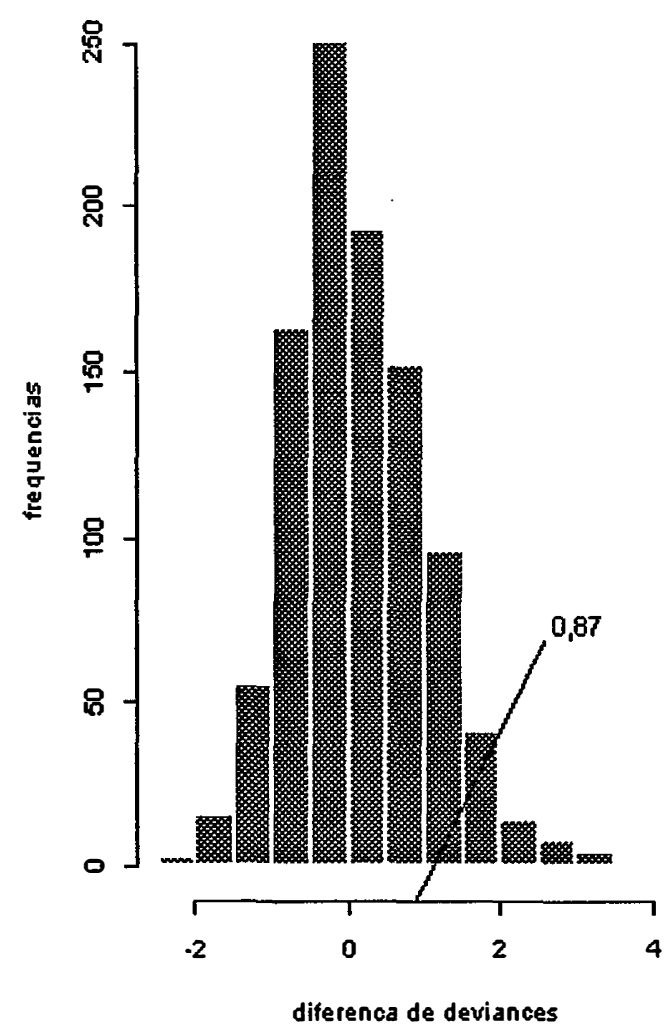

Modelo Logistico

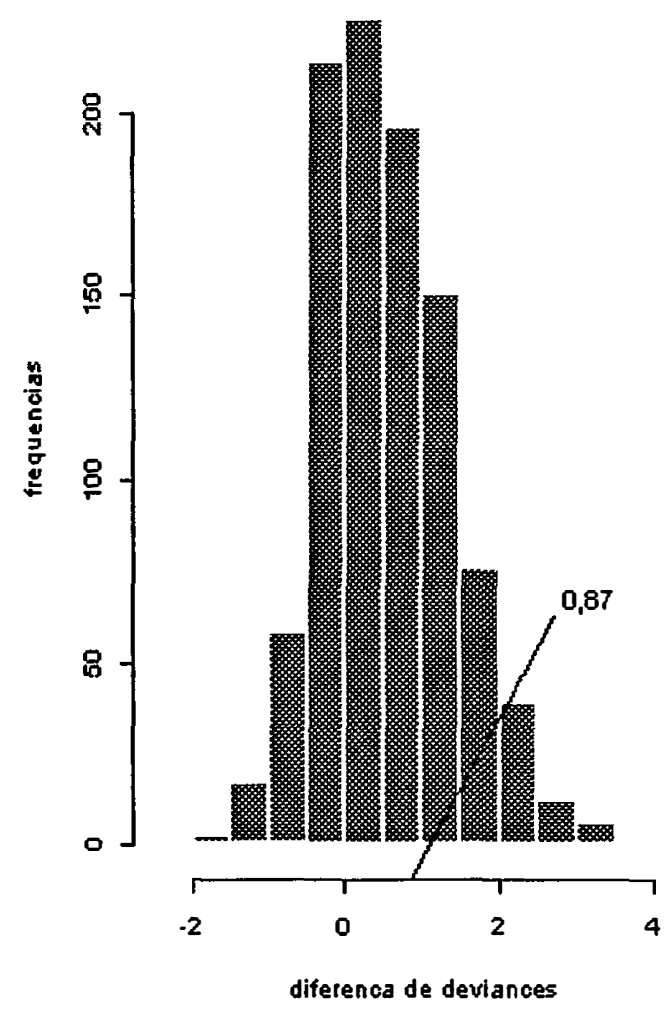

Figura 6 - Histograma da distribuição da diferença de deviances obtidas através de 1000 replicações bootstrap considerando os resíduos de Pearson padronizados no ajuste dos modelos de Cox e logístico para os dados do experimento com cultivar de linho. 


\subsection{Aplicaçāo com inseto}

Neste experimento os fatores envolvidos foram intervalo, grupo, que consistia de duas dietas dadas ao inseto Podysus nigrispinus, sendo uma constituída da larva infectada com AgNPV (grupo tratado) e a outra com a larva sadia (grupo controle) e sexo. O interesse foi avaliar se esses fatores influenciaram na probabilidade do inseto Podysus nigrispinus chegar a fase adulta em determinado intervalo, dado que não chegou no intervalo anterior. Devido aos poucos intervalos e aos empates, o tempo pode ser considerado como uma variável discreta e novamente os modelos de Cox e logístico podem ser ajustados. Analisando-se os resultados dos ajustes dos modelos para este experimento (Tabela 8), conclui-se que os fatores intervalo e sexo foram significativos para os dois modelos, mas o fator grupo foi significativo apenas para o modelo de Cox. A interação sexo*grupo não foi significativa em nenhum dos dois modelos considerados.

Tabela 8. Análise de deviances do experimento com inseto para os modelos de Cox e logístico.

\begin{tabular}{c|c|cc}
\hline Causas de Variação & GL & \multicolumn{2}{|c}{ Deviances } \\
& & Modelo de Cox & Modelo Logístico \\
\hline Nula & 15 & 162,373 & 162,373 \\
Intervalo & 4 & $140,738^{* *}$ & $140,738^{* *}$ \\
Sexo & 1 & $8,463^{* *}$ & $9,612^{* *}$ \\
Grupo & 1 & $4,104^{*}$ & $2,006^{n s}$ \\
Sexo*Grupo & 1 & $0,725^{n s}$ & $0,411^{n s}$ \\
Residual & 8 & 8,343 & 9,606 \\
\hline
\end{tabular}

** - significativo a $1 \%,{ }^{*}$ - significativo a $5 \%$, ns - não significativo

Portanto, as deviances residuais para os ajustes finais dos modelos de Cox (retirando-se a interação sexo ${ }^{*}$ grupo) e logístico (retirando-se a interação sexo * grupo e o fator grupo) são 9,068 e 12,023, respectivamente. Portanto a diferença 
de deviances observada, neste caso, foi de $d_{o b s}=-2,955$. Os valores dos AIC para os modelos de Cox e logístico foram respectivamente 59,829 e 60,784. A comparação entre as deviances e o AIC indicam que o modelo de Cox se adequa melhor aos dados.

Com base nestes resultados pode-se escrever $p_{i}\left(\mathbf{x}_{l}\right)$ para o modelo de Cox como:

$$
p_{i}\left(\mathbf{x}_{l}\right)=1-\left[\exp \left(-\exp \left(\gamma_{i}^{*}\right)\right)\right]^{\exp \left(\alpha_{j}+\tau_{r}\right)}
$$

em que:

- $p_{i}\left(\mathbf{x}_{l}\right)$ é a probabilidade do $l$-ésimo inseto chegar a fase adulta no $i$-ésimo intervalo, dado que não chegou até o intervalo anterior, considerando-se os fatores sexo e grupo.

- $\gamma_{i}^{*}$ é o efeito do $i$-ésimo intervalo, $i=1, \ldots, 5$;

- $\alpha_{j}$ é o efeito do $j$-ésimo sexo, $j=1,2$;

- $\tau_{r}$ é o efeito do $r$-ésimo grupo, $r=1,2$,

e, para o modelo logístico:

$$
p_{i}\left(\mathbf{x}_{l}\right)=1-\left[1+\exp \left(\gamma_{i}^{*}+\alpha_{j}\right)\right]^{-1}
$$

sendo:

- $p_{i}\left(\mathbf{x}_{l}\right)$ é a probabilidade do $l$-ésimo inseto chegar a fase adulta no $i$-ésimo intervalo, dado que não chegou até o intervalo anterior, considerando-se o fator sexo;

- $\gamma_{i}^{*}$ é o efeito do $i$-ésimo intervalo, $i=1, \ldots, 5$;

- $\alpha_{j}$ é o efeito do $j$-ésimo sexo, $j=1,2$.

As Figuras 7 e 8 apresentam as curvas de sobrevivência estimadas para o fator sexo segundo os modelos de Cox e logístico e a Figura 9 mostra a curva de sobrevivência estimada para o fator grupo considerando apenas o modelo de Cox, uma vez que este fator não foi significativo para o modelo logístico. 


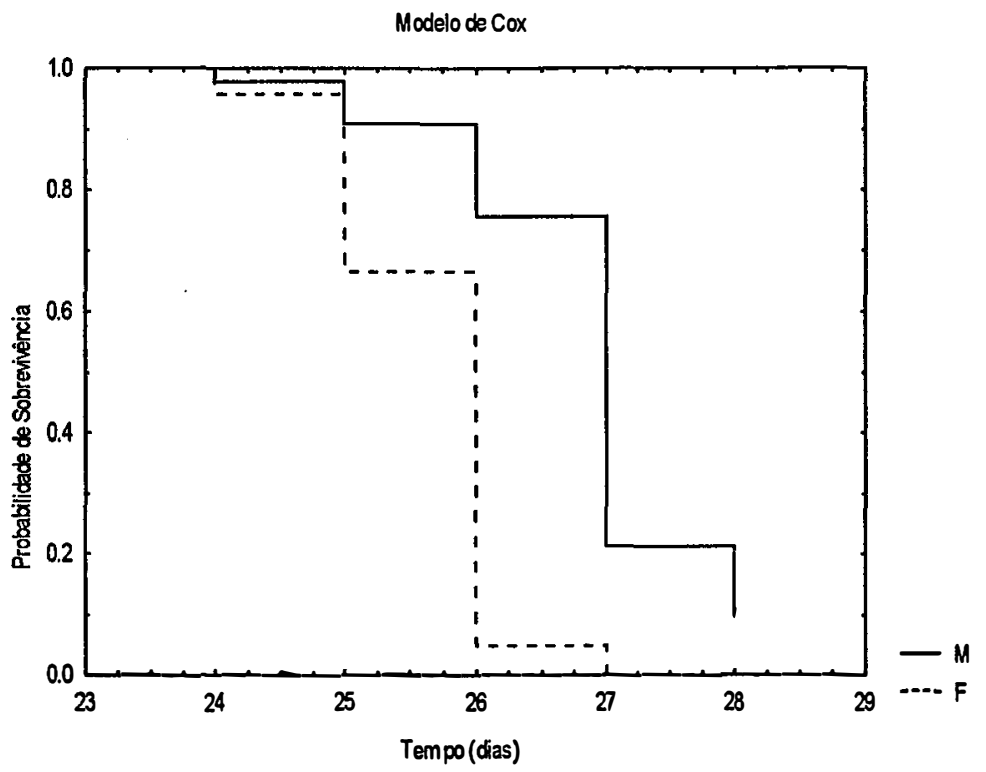

Figura 7 - Curva de sobrevivência estimadas segundo o sexo - Modelo de Cox.

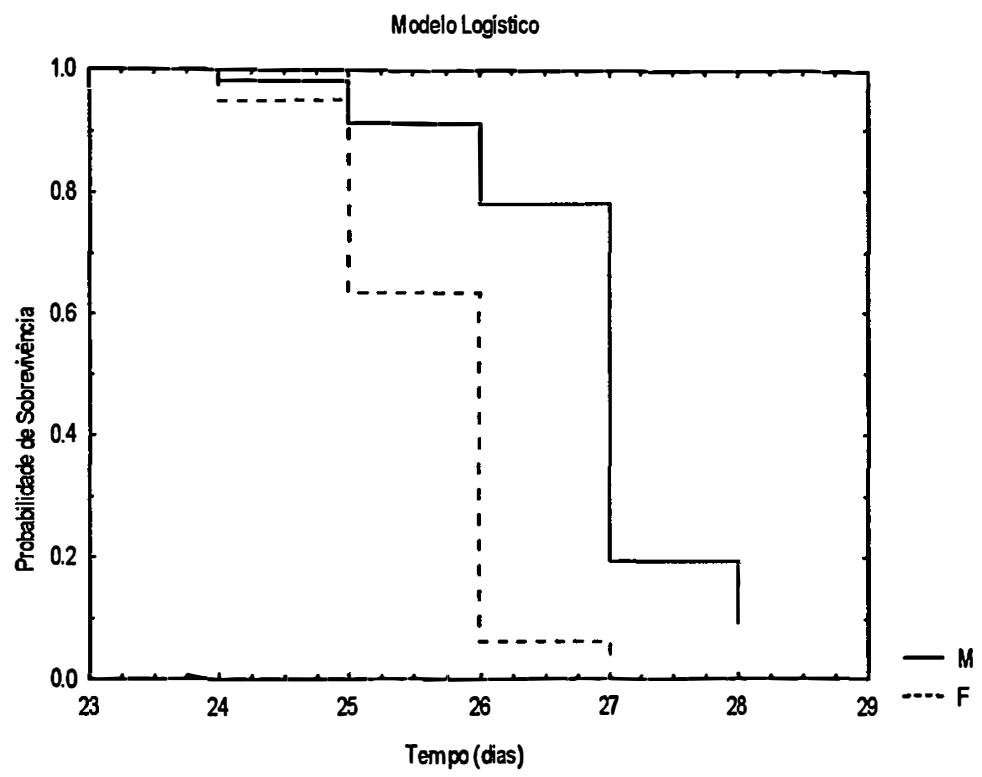

Figura 8 - Curva de sobrevivência segundo o sexo - Modelo logístico. 


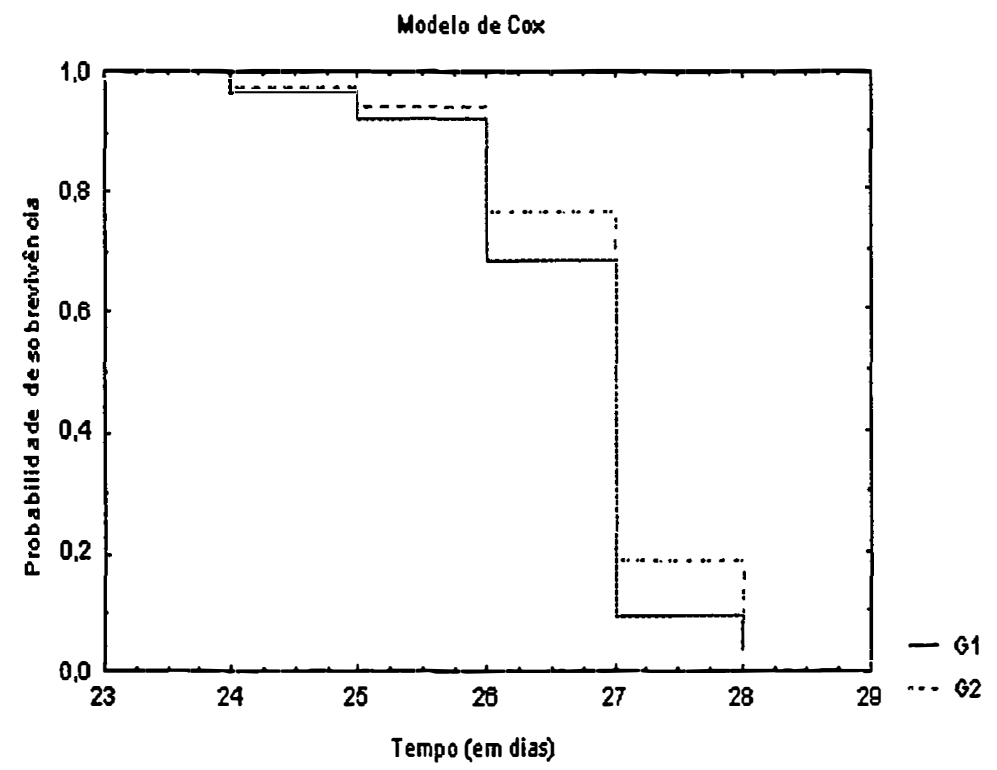

Figura 9 - Curva de sobrevivência segundo o grupo - Modelo de Cox.

As Tabelas 9 e 10 apresentam as estimativas dos parâmetros e seus erros padrões, segundo os modelos estudados.

Tabela 9. Estimativas dos parâmetros obtidas através do ajuste do modelo de Cox para os dados do experimento com insetos.

\begin{tabular}{c|cc}
\hline Parâmetros & estimativas & erro padrão \\
\hline$\gamma_{1}^{*}$ & $-2,4260$ & 0,6231 \\
$\gamma_{2}^{*}$ & $-1,6228$ & 0.7718 \\
$\gamma_{3}^{*}$ & $-0,7478$ & 0.6233 \\
$\gamma_{4}^{*}$ & 1,3073 & 0.5990 \\
$\gamma_{5}^{*}$ & 0,8512 & 0,6862 \\
$\alpha_{2}$ & -0.7942 & 0,2551 \\
$\tau_{2}$ & $-0,4820$ & 0,2380 \\
\hline
\end{tabular}


Tabela 10. Estimativas dos parâmetros obtidas através do ajuste do modelo logístico para os dados do experimento com insetos.

\begin{tabular}{c|cc}
\hline Parâmetros & estimativas & erro padrão \\
\hline$\gamma_{1}^{*}$ & $-2,5273$ & 0,6227 \\
$\gamma_{2}^{*}$ & $-1,4278$ & 0.8112 \\
$\gamma_{3}^{*}$ & $-0,6629$ & 0.6458 \\
$\gamma_{4}^{*}$ & 2,2519 & 0.6755 \\
$\gamma_{5}^{*}$ & 1,2225 & 0.8210 \\
$\alpha_{2}$ & $-1,1562$ & 0,3876 \\
\hline
\end{tabular}

Com base nesses resultados pode-se calcular as razões de risco para os fatores considerados, de acordo com o modelo adotado. A Tabela 11 apresenta as razões de risco e o $p$ - valor correspondente. De acordo com os modelos adotados tem-se, por exemplo, que o risco de uma fêmea atingir a idade adulta é 2,21 vezes o risco dos machos, quando considerado o modelo de Cox. Já para o modelo logístico esse mesmo risco é de 3,18.

Com relação ao fator grupo (tratamento), que foi significativo apenas no modelo de Cox, tem-se que o risco de um inseto que se alimentou da larva sadia (grupo controle) atingir a fase adulta é de 1,62 vezes mais que o dos insetos alimentados da larva infectada com AgNPV (grupo tratado).

Tabela 11. Razão de risco e $p$-valor segundo o modelo adotado.

\begin{tabular}{c|cc|cc}
\hline \multirow{2}{*}{ Parâmetros } & \multicolumn{2}{|c|}{ Razão de risco } & \multicolumn{2}{c}{$p$-valor } \\
\cline { 2 - 5 } & Modelo de Cox $\cdot$ Modelo Logístico & Modelo de Cox & Modelo Logístico \\
\hline F/M & 2,21 & 3,18 & 0,0018 & 0,0028 \\
C/T & 1,62 & - & 0,0428 & - \\
\hline
\end{tabular}


Para discriminar entre os modelos, trabalhou-se inicialmente com o modelo logístico incluindo o fator grupo, embora este fator não tenha sido significativo para este modelo. Neste caso a $d_{o b s}=-0,949$ e, portanto, se espera que o modelo mais adequado apresente uma maior concentração de valores à esquerda da $d_{o b s}$ na distribuição empírica da diferença de deviances do que o outro modelo. Pela análise das Figuras 10, 11 e 12 percebe-se que o modelo de Cox é então o mais adequado.

Na Tabela 12 encontram-se os níveis de significância empíricos considerando os tipos de resíduos e os modelos estudados. De acordo, com os resultados obtidos há uma indicação de que o modelo de Cox se adequa melhor aos dados. Com relação aos tipos de resíduos considerados, verifica-se que o resíduo simples é o único que apresenta níveis de significância próximos para os dois modelos, já os resíduos de Pearson e Pearson padronizados sugerem o modelo de Cox como mais adequado.

Tabela 12. Níveis de significância obtidos através de 1000 replicações bootstrap segundo o tipo de resíduo e os modelo de Cox e logístico (com grupo) para o experimento com inseto.

\begin{tabular}{c|c|c}
\hline \multirow{2}{*}{ Tipos de resíduos } & \multicolumn{2}{|c}{ Modelos } \\
\cline { 2 - 3 } & Cox & Logístico \\
\hline Simples & 0,505 & 0,439 \\
Pearson & 0,479 & 0,148 \\
Pearson padronizado & 0,505 & 0,154 \\
\hline
\end{tabular}


Modelo de Cox

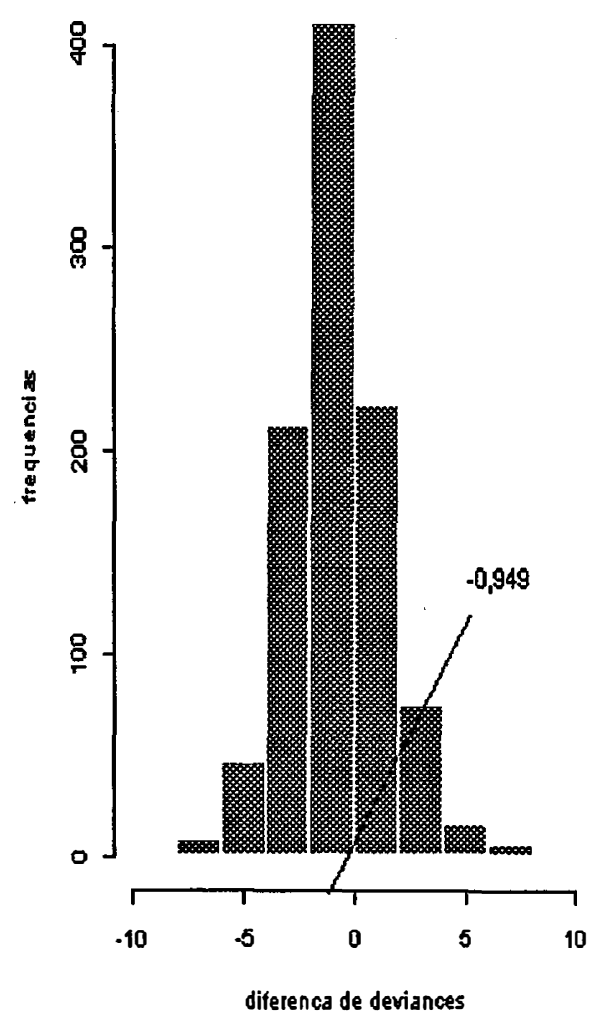

Modelo Logistico

corn grupo

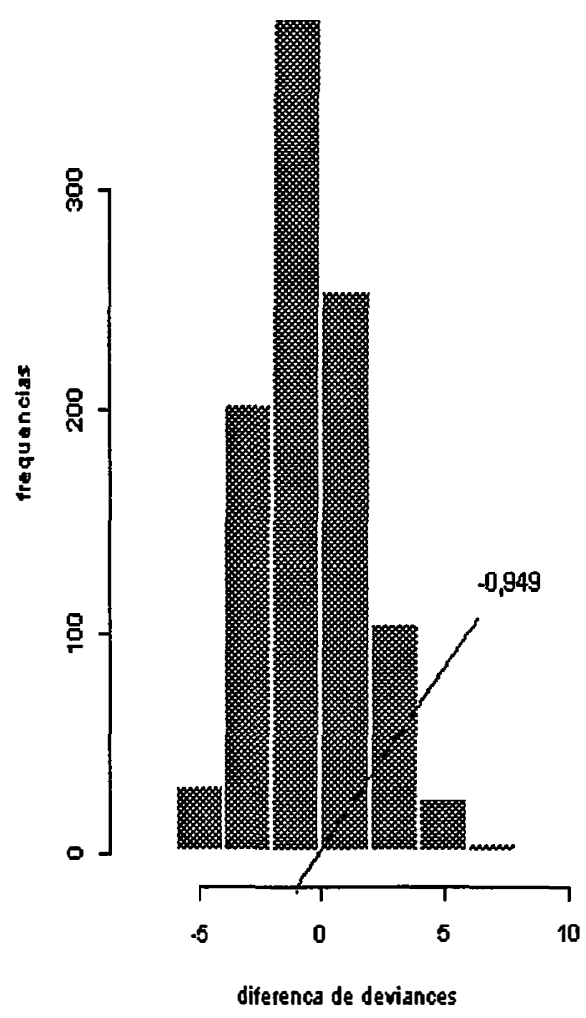

Figura 10 - Histograma das diferenças de deviances obtidas através de 1000 replicações bootstrap dos resíduos simples no ajuste dos modelos de Cox e logístico (com o fator grupo) para os dados do experimento com inseto. 

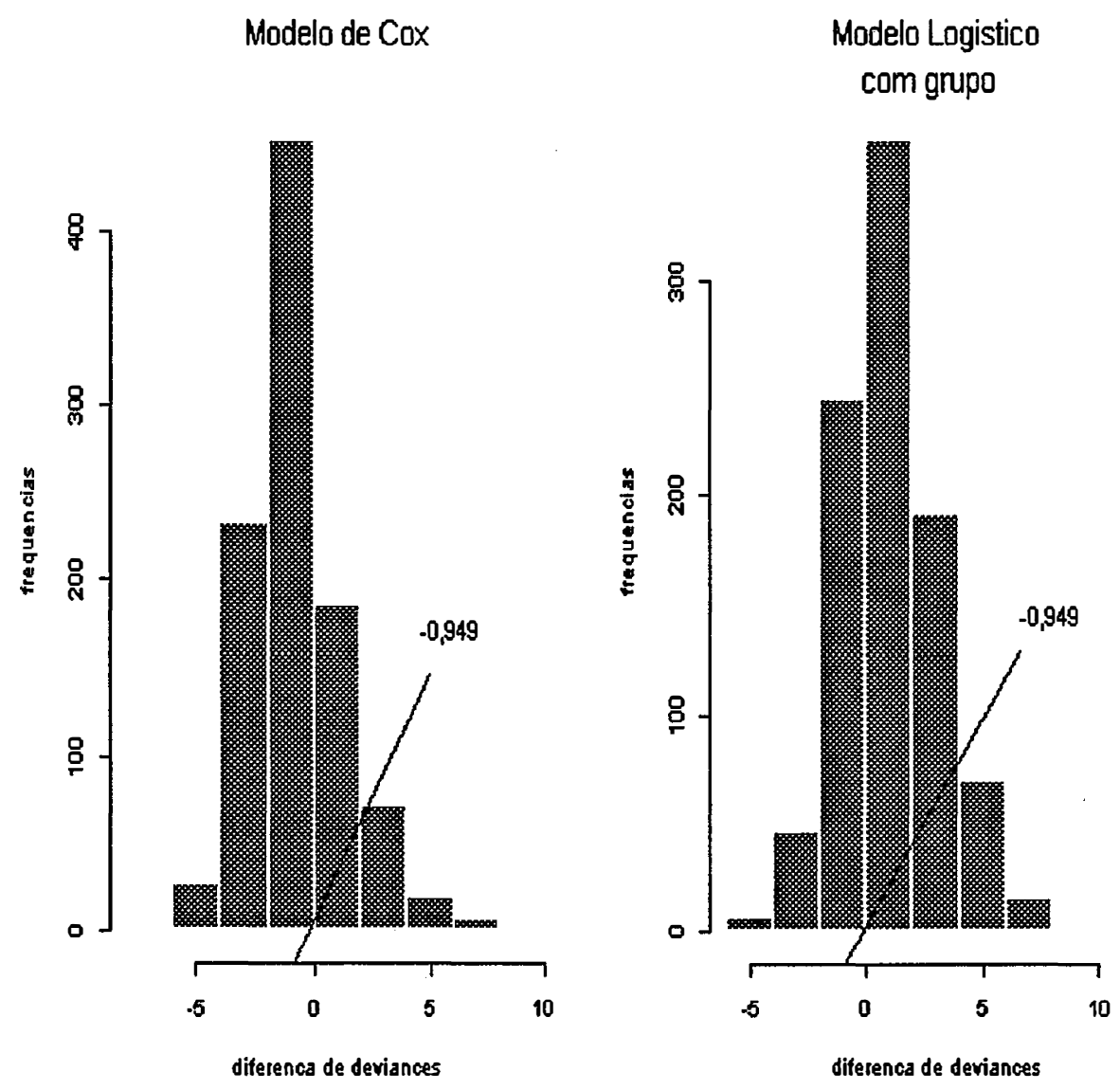

Figura 11 - Histograma das diferenças de deviances obtidas através de 1000 replicações bootstrap dos resíduos de Pearson no ajuste dos modelos de Cox e logístico (com o fator grupo) para os dados do experimento com inseto. 

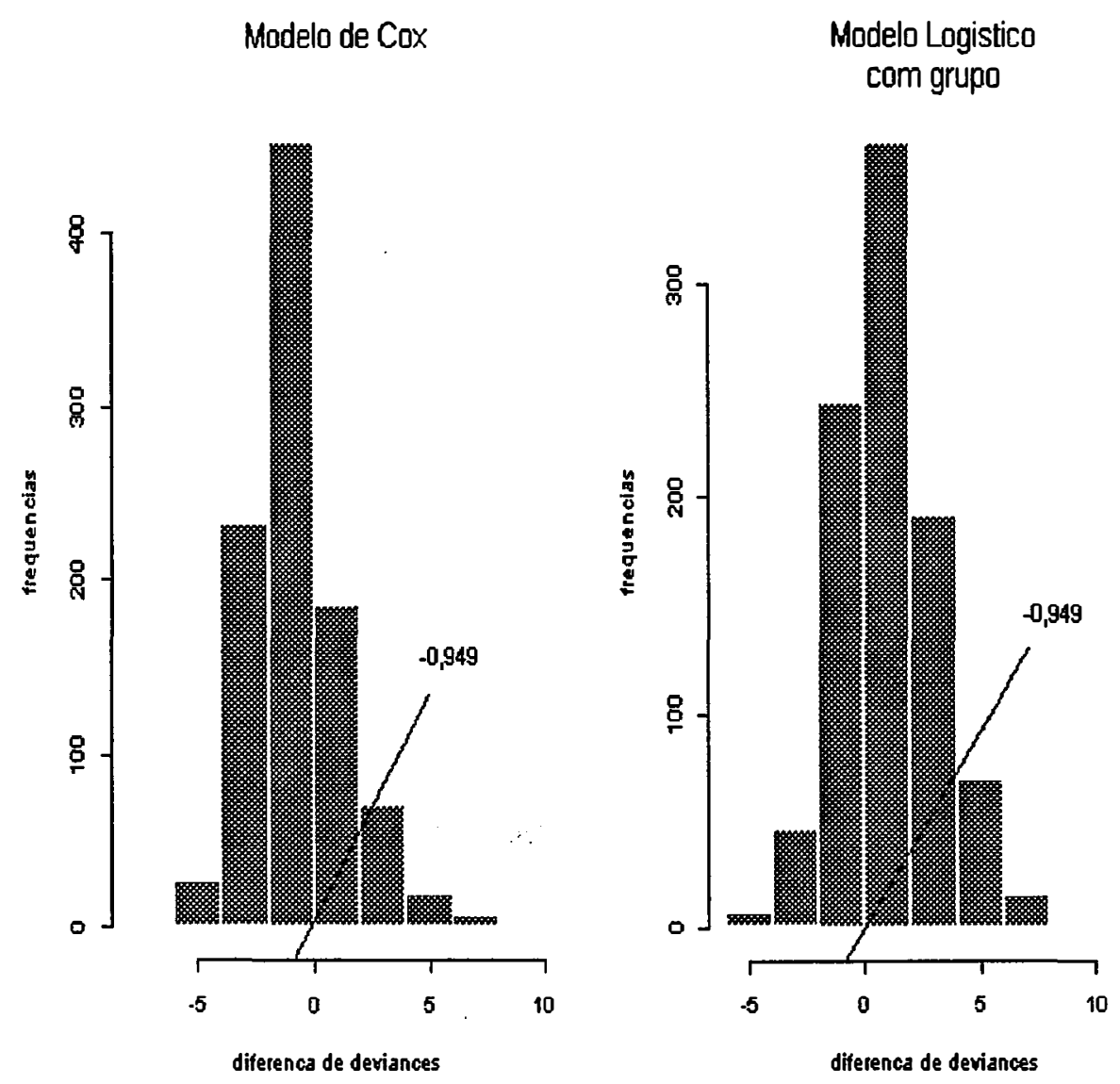

Figura 12 - Histograma das diferenças de deviances obtidas através de 1000 replicações bootstrap dos resíduos de Pearson padronizados no ajuste dos modelos de Cox e logístico (com o fator grupo) para os dados do experimento com inseto. 
As Figuras 13, 14 e 15 apresentam as distribuições empíricas da diferença de deviances excluindo o fator grupo do modelo logístico. Nesse caso a diferença de deviances observada foi $d_{o b s}=-2,955$, ou seja, espera-se que o melhor modelo apresente maior concentração de valores à esquerda da $d_{\text {obs }}$. A discriminação entre os modelos foi bem mais evidente quando utilizou-se o resíduo de Pearson, embora os outros dois tipos de resíduos também tenham apresentado um maior nível de significância para o modelo de Cox.

Tabela 13. Níveis de significância obtidos através de 1000 replicações bootstrap segundo o tipo de resíduo e os modelo de Cox e logístico (sem grupo) Experimento com inseto.

\begin{tabular}{c|c|c}
\hline Tipos de resíduos & \multicolumn{2}{|c}{ Modelos } \\
\cline { 2 - 3 } & Cox & Logístico \\
\hline Simples & 0,711 & 0,639 \\
Pearson & 0,694 & 0,103 \\
Pearson padronizado & 0,374 & 0,100 \\
\hline
\end{tabular}



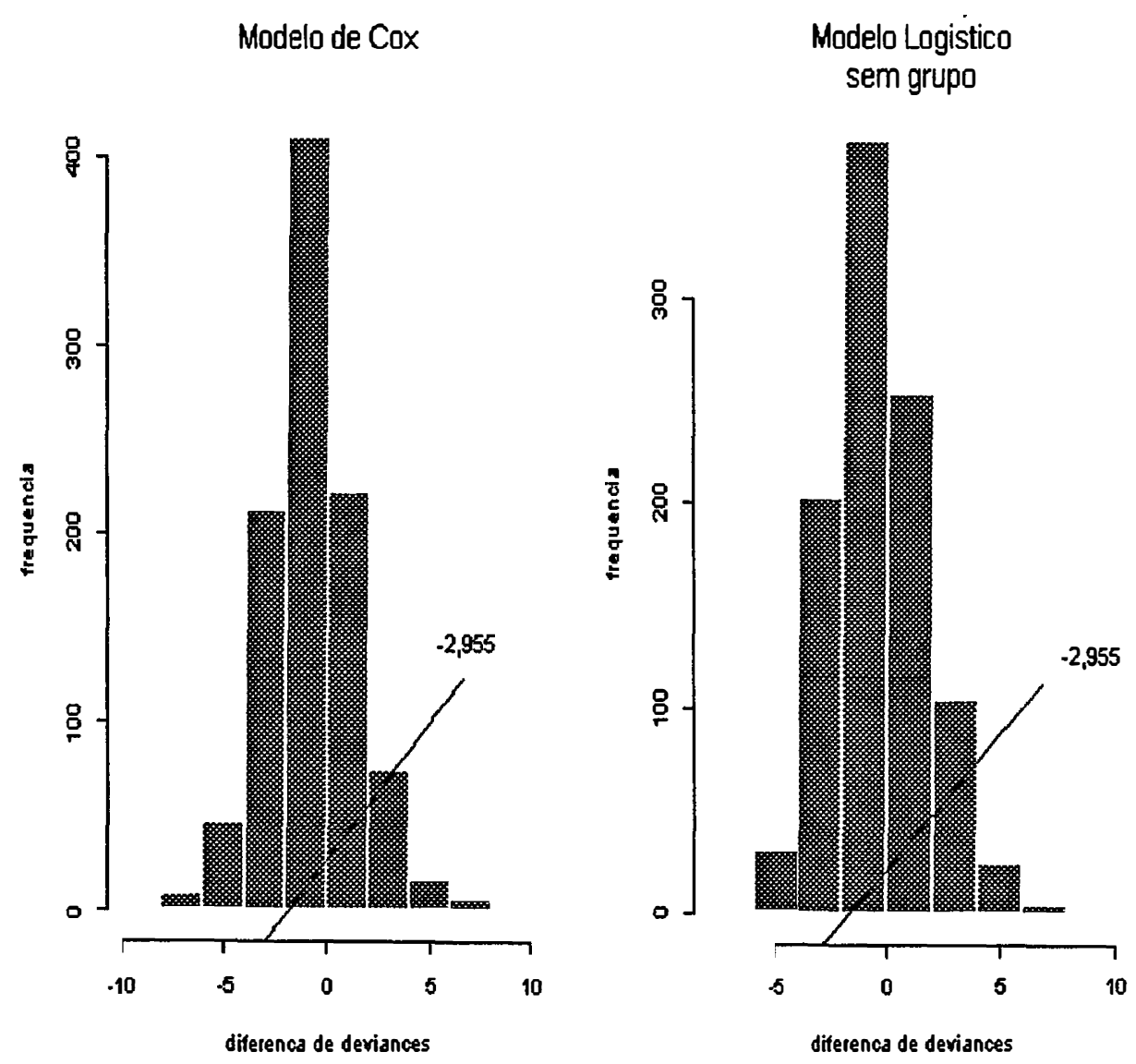

Figura 13 - Histogramas das diferenças de deviances obtidas através de 1000 replicações bootstrap considerando-se os resíduos simples no ajuste dos modelos de Cox e logístico para os dados do experimento com inseto (sem o fator grupo). 

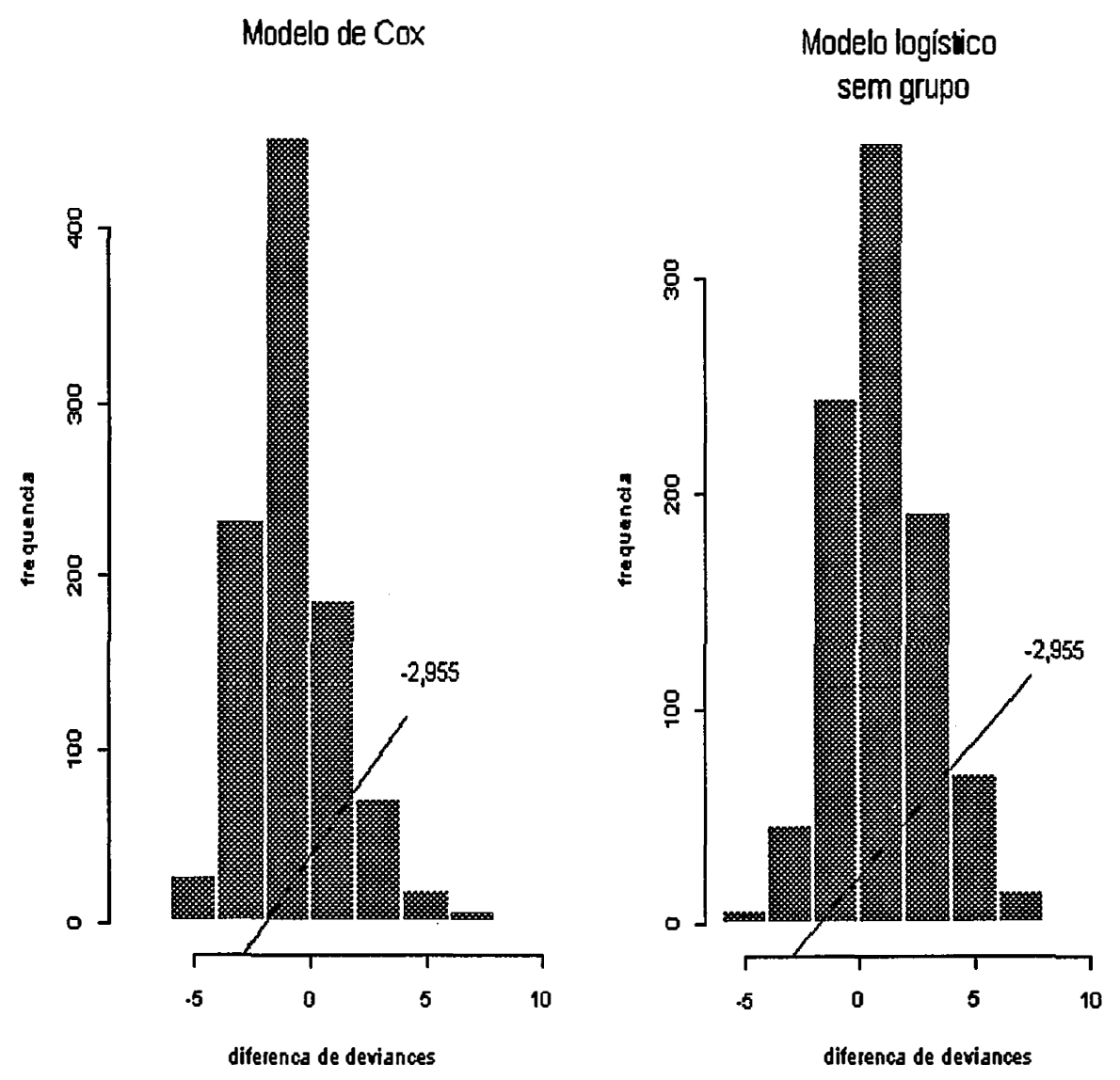

Figura 14 - Histogramas das diferenças de deviances obtidas através de 1000 replicações bootstrap considerando-se os resíduos de Pearson no ajuste dos modelos de Cox e logístico para os dados do experimento com inseto (sem o fator grupo). 

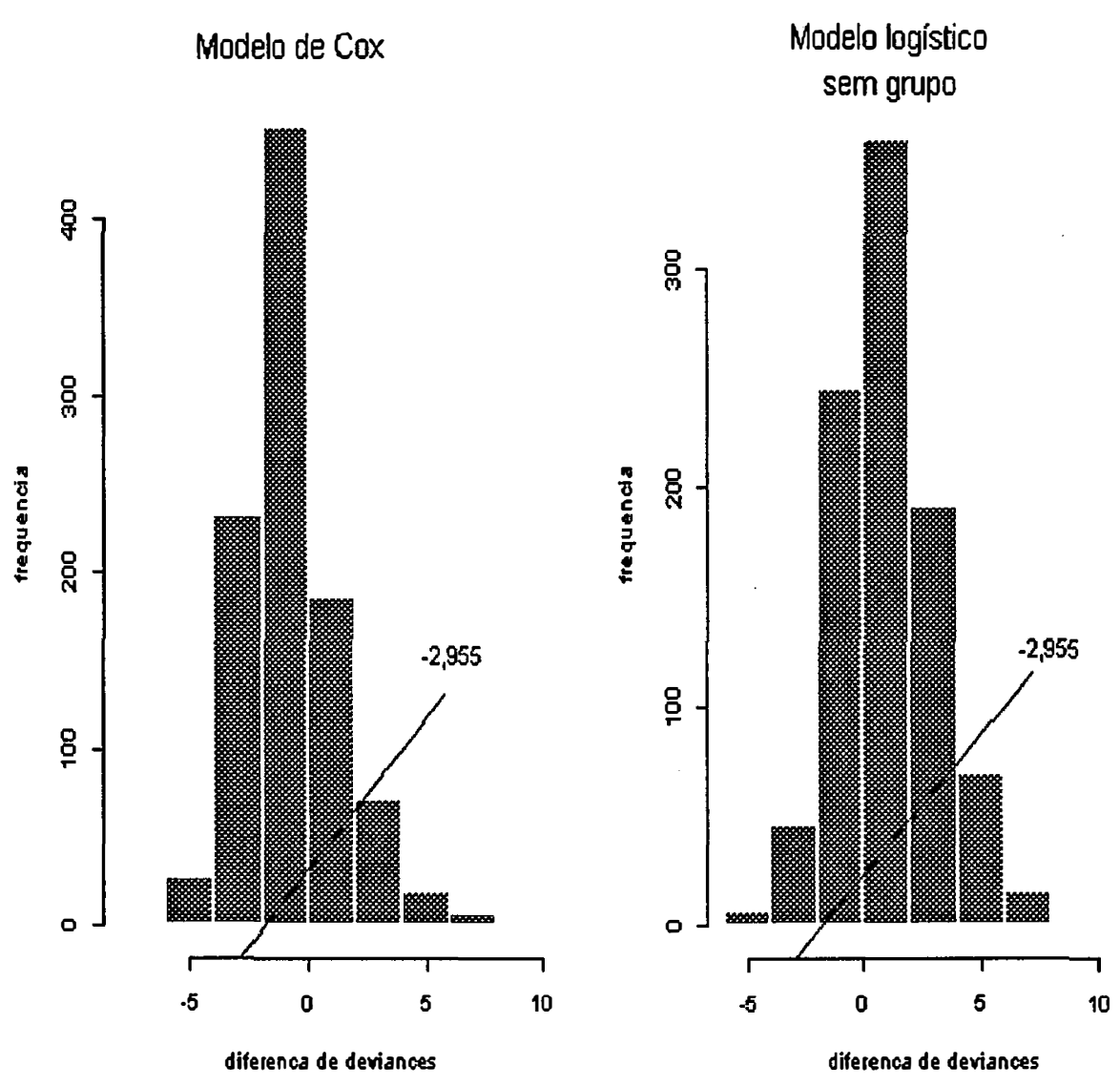

Figura 15 - Histogramas das diferenças de deviances obtidas através de 1000 replicações bootstrap considerando-se os resíduos de Pearson padronizados no ajuste dos modelos de Cox e logístico para os dados do experimento com inseto (sem o fator grupo). 


\section{CONCLUSÕES}

De acordo com a metodologia desenvolvida e com as análises dos dados dos experimentos considerados, pode-se concluir que:

- quando se tem dados com censura intervalar e o número de empates é grande, o ajuste dos modelos de Cox e logístico se torna simples através dos modelos lineares generalizados, facilitando a obtenção de resíduos e, consequentemente, do processo de reamostragem;

- na análise dos dados do experimento com o linho, observou-se um pequeno valor para a diferença de deviances, e ainda assim, através da metodologia bootstrap proposta, foi possível evidenciar uma indicação do modelo logístico como o que melhor se adequa aos dados;

- com relação a análise dos dados do experimento com o inseto, novamente se observou um pequeno valor para a diferença de deviances na presença do fator grupo no modelo logístico, mas que ainda assim, o método apontou o modelo de Cox como o que melhor se adequa aos dados; sem considerar o fator grupo no modelo logístico, a diferença de deviances foi maior, e novamente houve a indicação do modelo de Cox como o mais adequado, através da metodologia proposta;

- comparando-se os níveis de significância obtidos para os três tipos de resíduos considerados (resíduos simples, de Pearson e Pearson padronizados), notase que o resíduo de Pearson e o de Pearson padronizado produzem valores próximos, sendo os responsáveis na indicação do melhor modelo; 
- pode-se notar que, quando a diferença de deviances é um valor pequeno, os níveis de significância empíricos calculados mostram poucas evidências na indicação do melhor modelo, o que já não acontece quando esse valor é grande;

Como sugestão para a continuidade deste estudo, simulações poderiam ser feitas, considerando-se um dos modelos como o verdadeiro, e verificando-se, portanto, a eficiência do método bootstrap proposto na escolha do modelo. Além disso, seria interessante considerar vários valores de diferenças de deviances para se ter uma regra empírica de discriminação através do método sugerido aqui, ou seja, considerar diversos valores nas diferenças de deviances e verificar o comportamento do método com relação a essa variação.

Outro ponto a ser levado em conta seria utilizar o esta técnica considerando outros tipos de resíduos como, por exemplo, o resíduo de deviance, o resíduo de deviance padronizado e o resíduo padronizado na escala do predito linear, e verificar a eficiência do método na discriminação de modelos. 


\section{REFERÊNCIAS BIBLIOGRÁFICAS}

AKAIKE, H. Information theory and an extension of the maximum likelihood principle. In: KOTZ, S.; JOHNSON, N.L. (Ed.) Breakthroughs in statistics. New York: Springer, 1973. v.1, p.610-624.

ALLISON, P. D. Survival analysis using the SAS system: a pratical guide. Cary: SAS Institute, 1995. 292p.

ARANDA-ORDAZ, F. J. On two families of transformations to additivity for binary response data. Biometrika, v.68, n.2, p.357-364, 1981.

BICKEL. J.; FREEDMAN, D.A. Some asymptotic theory for the bootstrap. The Annals of Statistics, v.9, p.1196-1217, 1981.

BRESLOW, N. Contribution to discussion of paper by D. R. Cox. Journal of Royal Statistical Society. Series B, v.34, p.216-217, Mar. 1972.

BRESLOW, N. Covariance analysis of censored survival data. Biometrics, v.30, n.1, p.89-99, Mar. 1974.

CHALITA, L.V.A.S. Modelos para dados agrupados e censurados. Piracicaba, 1997. 135p. Tese (Doutorado) - Escola Superior de Agricultura "Luiz de Queiroz", Universidade de São Paulo.

COLLETT, D. Modelling binary data. London: Chapman \& Hall, 1991. 369p.

COLLETT, D. Modelling survival data in medical research. London: Chapman \& Hall, 1994. 347p. 
COlOsimo, E.A.; CHAlitA, L.V.A.S.; DEMÉTRIO, C.G.B. Tests of proportional hazards and proportional odds models for Grouped survival data. Biometrics, v.56, n.4, p.1233-1240, Dec. 2000.

CORDEIRO, G.M. Modelos lineares generalizados. Campinas: ABE, 1986. 286p.

COX, D.R. Further results on tests of separate families of hipotheses. Journal of the Royal Statistical Society. Series B, v.24, p.406-424, 1962.

COX, D.R. Regression models and life-tables (with discussion). Journal of Royal Statistical Society. Series B, v.34, p.187-220, Mar. 1972.

COX, D.R. Partial likelihood. Biometrika, v. 62, n.2, p.269-276, Mar. 1975.

COX, D.R.; OAKES, D. Analysis of survival data. London: Chapman \& Hall, 1984. 195p.

DAVISON, A.C.; HINKLEY, D.V. Bootstrap methods and their application. Cambridge: University Press, 1997. 575p.

DEMÉTRIO, C.G.B. Modelos lineares generalizados na experimentação agronômica. Porto Alegre: UFRGS, Depto. de Estatística, 1993. 125p.

DOBSON A.J. An introduction to generalized linear models. London: Chapman \& Hall, 1990. 174p.

EFRON, B. The efficiency of Cox's likelihood function for censored data. Journal of the American Statistical Association, v.72, n.359, p.557-565, 1977.

EFRON, B. Bootstrap methods: another look at jackknife. Annals of Statistics, v.7, p-1-26, 1979.

EFRON, B. Comparing non-nested linear models. Journal of the American Statistical Association, v.79, p.791-803,1984. 
EFRON, B. ; TIBISHIRANI, R.J. An introduction to the bootstrap. New York: Chapman \& Hall, 1993. 436p.

FAREWELL, V. T.; PRENTICE, R. L. The aproximation of partial likelihood with emphasis on case-control studies. Biometrika, v.67, n.2, p.273-279, 1980.

FAY, M. P. Comparing several score tests for interval censored data. Statistics in Medicine, v.18, p.273-285, 1999.

FINKELSTEIN, D. M. A Proportional hazards model for interval-censored failure time Data. Biometrics, v.42, n.4, p.845-854, 1986.

FREEDMAN, D.A. Bootstrapping regression models. Annals of Statistics, v.9, p.1218-1228, 1981.

HALL, P. The bootstrap and edgeworth expansion. New York: Springer, 1992. 352p.

HINKLEY, D.V. Bootstrap methods. Journal of the Royal Statistical Society. Series B, v.50, n.3, p.321-337, 1988.

KALBFLEISH, J.D.; PRENTICE, R.L. Marginal likelihoods based on Cox's regression and life model. Biometrika, v.60, p.267-279, Mar. 1973.

KALBFLEISH, J.D.; PRENTICE, R.L. The Statistical analysis of failure time data. New York: John Wiley, 1980. 321p.

KAPLAN, E.L.; MEIER, P. Nonparametric estimation from incomplete observations. Journal of American Statistical Association, v.53, p.457-481, May 1958.

LAWLESS, J. F. Statistical models and methods for lifetime data. New York: John Wiley, 1982. 579p.

LINDSEY, J.K.; JONES, B. Choosing among generalized linear models applied to medical data. Statistics in Medicine, v.17, p.59-68, 1998. 
McCULLAGH, P.; NELDER, J.A. Generalized linear models. 2.ed. London: Chapman \& Hall, 1989. 511p.

MOULTON, L.H.; ZEGER, S.L. Analyzing repeated measures on generalized linear Models via the Bootstrap. Biometrics, v.45, p. 381-394, 1989.

MOULTON, L.H.; ZEGER, S.L. Bootstrapping generalized linear models. Computational Statistics and Data Analysis, v.11, p.53-63, 1991.

NELDER, J.A.; WEDDERBURN, R.W.M. Generalized linear models. Journal of the Royal Statistical Society. Series A, v.135, p.370-384, 1972.

PETO, R. Contribution to dicussion of paper by D.R. COX. Journal of the Royal Statistical Society. Series B, v.34, p.205-207, 1972.

PRENTICE, R. L.; L. A. GLOECKLER. Regression analysis of grouped survival data with application to breast cancer data. Biometrics, v.34, n.1, p.57-67, 1978.

SCHWARTZ, G. Estimating the dimensions of a model. Annals of Statistics, v.6, n.2, p.461-463, 1978.

SHAO, J. Bootstrap model selection. Journal of the American Statistical Association, v.91, p.655-665, 1996.

SILVA, D.N. O método bootstrap e aplicações à regressão múltipla. Campinas, 1995. 158p. Dissertação (Mestrado) - Instituto de Matemática Estatística e Computação, Universidade Estadual de Campinas.

STATISTICAL SCIENCE. S-Plus for Windows: user's manual. Seattle, 1993. $2 \mathrm{v}$.

SUN, J. A non-parametric test for interval-censored failure time data with applications to AIDS studies. Statistics in Medicine, v.15, p.1387-1395, 1996. 
THOMPSON, JR., W.A. On the treatment of grouped observations in life studies. Biometrics, v. 33, p. 463-470, June 1977.

WHITEHEAD, J. The analysis of colapse clinical trials, with application to a comparison of two ulcer treatments. Statistics in Medicine, v.8, p.1439$1454,1989$.

WILLIAMS, D.A. Discrimination between regression models to determine the patern of enzyme synthesis in cell cultures. Biometrics, v.28, n.1 p.23-32, 1970. 
Apêndice: Dados 
Tabela 1. Dados obtidos do experimento com cultivar de linho.

\begin{tabular}{|c|c|c|c|}
\hline Tempo & Solo & Número de plantas murchas & Número de censuras \\
\hline 21 & $\mathrm{M}$ & 5 & 66 \\
\hline 24 & $\mathbf{M}$ & 8 & 58 \\
\hline 28 & M & 13 & 45 \\
\hline 31 & M & 10 & 35 \\
\hline 35 & M & 11 & 24 \\
\hline 38 & M & 16 & 8 \\
\hline 42 & M & 4 & 4 \\
\hline 45 & $\mathbf{M}$ & 2 & 2 \\
\hline 49 & M & 1 & 1 \\
\hline 21 & MI & 2 & 70 \\
\hline 24 & MI & 6 & 64 \\
\hline 28 & MI & 7 & 57 \\
\hline 31 & MI & 12 & 45 \\
\hline 35 & MI & 10 & 35 \\
\hline 38 & MI & 12 & 23 \\
\hline 42 & MI & 8 & 15 \\
\hline 45 & MI & 8 & 7 \\
\hline 49 & MI & 3 & 4 \\
\hline 21 & MK & 1 & 70 \\
\hline 24 & MK & 14 & 56 \\
\hline 28 & MK & 8 & 48 \\
\hline 31 & MK & 11 & 37 \\
\hline 35 & MK & 10 & 27 \\
\hline 38 & MK & 14 & 13 \\
\hline 42 & MK & 4 & 9 \\
\hline 45 & MK & 6 & 3 \\
\hline 21 & $\mathrm{MM}$ & 1 & 71 \\
\hline 24 & MM & 2 & 69 \\
\hline 28 & MM & 3 & 66 \\
\hline 31 & MM & 12 & 54 \\
\hline 35 & MM & 13 & 41 \\
\hline 38 & MM & 16 & 25 \\
\hline 42 & $\mathrm{MM}$ & 8 & 17 \\
\hline 45 & $\mathrm{MM}$ & 9 & 8 \\
\hline 49 & MM & 5 & 3 \\
\hline
\end{tabular}


Tabela 2. Dados obtidos do experimento com inseto Podysus nigrispinus.

\begin{tabular}{c|c|c|c|c}
\hline Tempo & Sexo & Grupo & Número de adultos & Número de censuras \\
\hline 24 & M & 1 & 1 & 29 \\
25 & M & 1 & 1 & 28 \\
26 & M & 1 & 4 & 24 \\
27 & M & 1 & 21 & 3 \\
28 & M & 1 & 1 & 2 \\
26 & F & 1 & 8 & 12 \\
27 & F & 1 & 12 & 0 \\
24 & M & 2 & 1 & 28 \\
25 & M & 2 & 3 & 25 \\
26 & M & 2 & 3 & 22 \\
27 & M & 2 & 14 & 8 \\
28 & M & 2 & 4 & 4 \\
24 & F & 2 & 1 & 20 \\
26 & F & 2 & 6 & 14 \\
27 & F & 2 & 11 & 3 \\
28 & F & 2 & 3 & 0 \\
\hline
\end{tabular}

